\title{
Social affiliation needs as a motivator of risky online behaviour
}

An empirical Research Project presented to the

\section{School of Information Management}

\section{Victoria University of Wellington}

by

Antony Zogg, Student ID: 300170000

in partial fulfilment of the requirements for the MMIM592

20 June 2011

Word Count: 20,558

\section{Declaration}

1. I know that plagiarism is wrong. Plagiarism is to use another's work and pretend that it is one's own.

2. I have used the APA convention for citation and referencing. Each contribution to, and quotation in, this Research Project entitled "Social affiliation needs as a motivator of risky online behaviour" from the work(s) of other people has been attributed, and has been cited and referenced.

3. This paper is my own work.

4. I have not allowed, and will not allow, anyone to copy my work with the intention of passing it off as his or her own work

5. I acknowledge that copying someone else's assignment, essay or paper, or part of it, is wrong, and declare that this is my own work.

Signature(s)

Date 20/06/11

Full name(s) of student(s) Antony John Zogg 


\section{Abstract}

In spite of the risks, people often share large quantities of personal information online. The objective of this research was to gain an understanding as to why people take such risks when engaging with others on social networking sites like Facebook. Initially the existence of online communities had to be established, and consideration given to the possibility that these online communities reflected groups found in the real world. The following hypotheses were then tested using an online survey with Likert Scale questions and freeform questions. This data was then triangulated by and supplemented with data received as a result of semistructured interviews. Interview and survey questions were informed by a full literature review undertaken on the topic.

H1: Humans mimic online behaviours including risky behaviours to gain acceptance in online communities. There was insufficient support for this hypothesis. This may be due to the fact that online and real world groups differ in terms of the way in which they communicate. The five senses are not fully engaged in online communication and there is an absence of body language and other non-verbal communication. This difference may determine that there is less need for social affiliation online than in the real world.

H2: The need for personal safety online is secondary to the need for social affiliation. Again there was insufficient support for this hypothesis, and even those with online communities of trusted friends drawn from the real world were concerned for their personal safety and configured their privacy settings. However these people were comfortable sharing personal information online with trusted friends, demonstrating that they were under the illusion that their information was private.

H3: Humans reflect the values of their friends on social networks to gain their approval. This hypothesis was well supported and indications were that people were more prepared to share personal information online with those who shared their values. They are also unlikely to share controversial information that violated their personal values.

The results of this research were viewed through the lens of "The Online Disinhibition Effect" (Suler, 2004), and recommendations made to companies planning online business.

Keywords: Online communities; social affiliation; risky online behaviours; mimicry; value congruence; trust; information sharing; online disinhibition. 


\section{Preface}

The author wishes to acknowledge the following people for their support:

1. My wife Jacinta Zogg who has been a tower of strength to me. I do not believe that I have cooked a single meal or done a single chore around the house for longer than I can remember.

2. My friends Shane Hastie and Donald Peterkin for devoting 5 years of their lives trying to persuade me to enroll on the MIM, and for their continued encouragement and interest in my progress over the past 3 years.

3. My classmate Diederick Muller who has been a good friend and support through all of this.

4. My supervisor Tony Hooper who truly inspired me to embark on this research, and has been a constant friend and lecturer over the years. 


\section{Table of Contents}

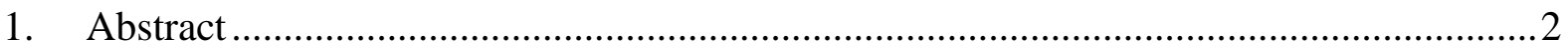

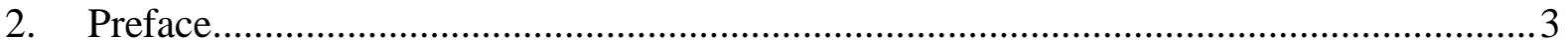

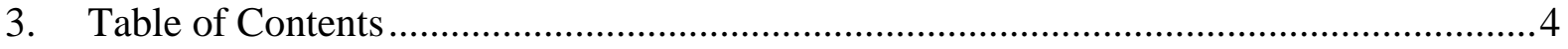

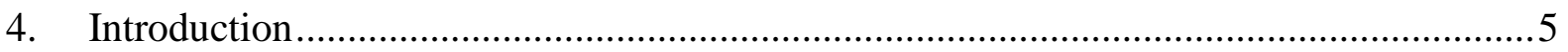

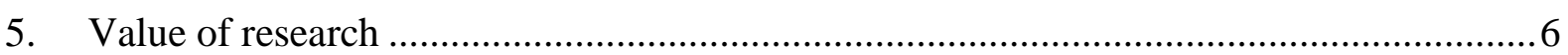

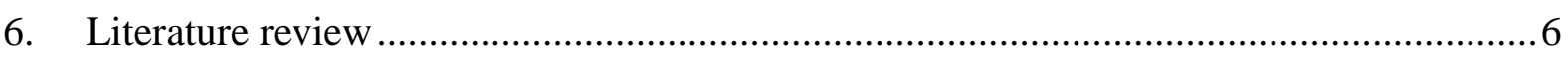

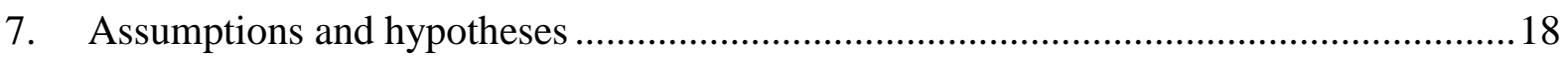

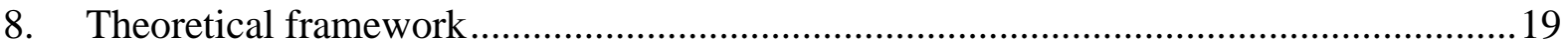

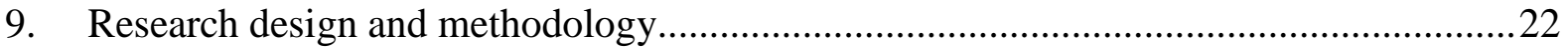

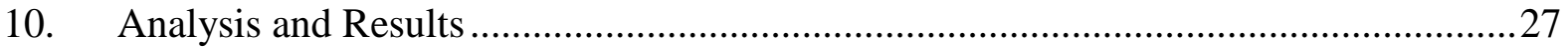

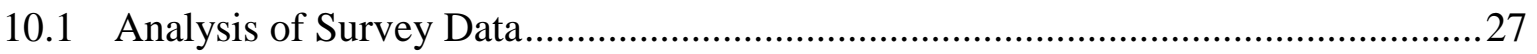

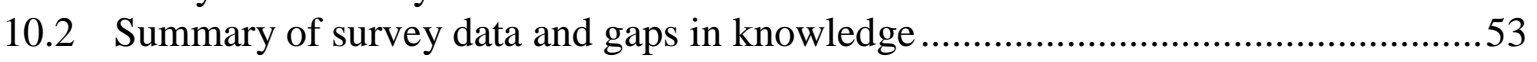

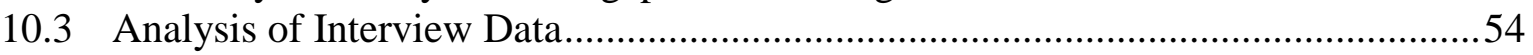

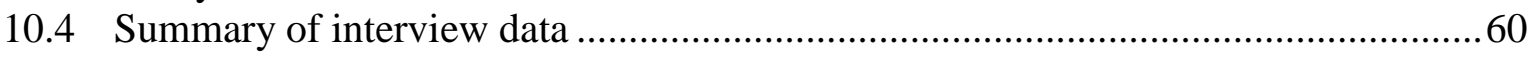

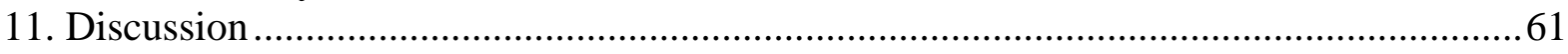

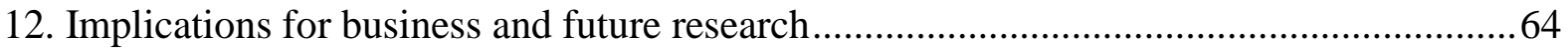

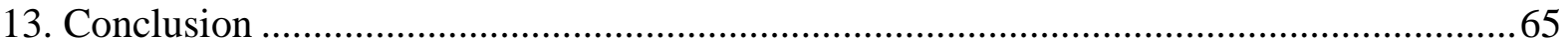

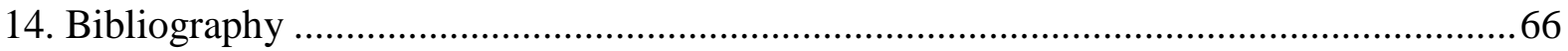

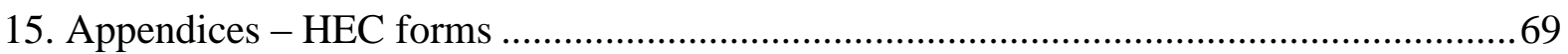

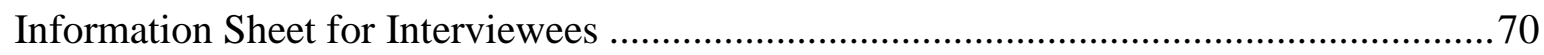

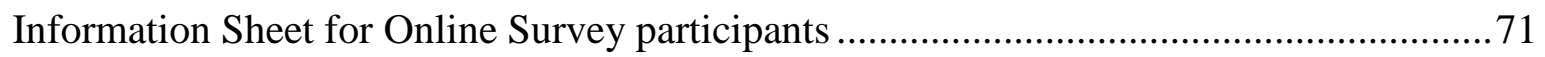

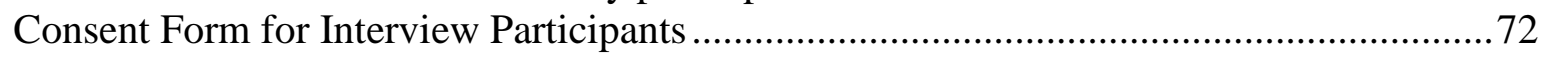




\section{Introduction}

This research was carried out in an attempt to find answers to the question: Are social affiliation needs the reason why people indulge in risky online behaviour?

These risky behaviours typically involve people posting large quantities of personal, sensitive and often intimate information about themselves online. These behaviours are commonplace on social networking sites, blogs, online forums, and in an infinite number of online situations/contexts where Web 2.0 technologies allow for user generated content.

In the offline /real world, when personal information is exchanged among group members, the people sharing that information can feel fairly confident that such information will be confined to members of the group, and that only a limited number of people will have access to it. A difficulty arises when people join communities like Facebook, and share personal information with their friends online. Unlike the sharing of information with friends and other group members in the real world, personal and intimate information shared online is accessible not only by the friends and groups for whom that information was intended, but also by a much wider and potentially infinite audience. Based on their experiences of trusted group memberships in the real world, people can be deceived into believing that online communities and groups can afford them the privacy they enjoyed in the offline world.

The consequences of posting too much personal information online can lead to issues like decreased employability, loss of professional credibility, sale of personal information to marketing companies, identity theft and victimization by sexual predators among many others.

This research attempted to find answers as to why people take such risks online. In the media, much has been written and reported over the years about privacy and personal safety on social networks; however, people still persist in posting large amounts of information about themselves online.

A possible explanation for risky online behaviour may be that online communities exist and actually do reflect social groups in the real world. If these real world groups and online communities are the same, one could reasonably assume that social affiliation behaviours in the real world also occur in online communities. The literature review that follows demonstrates that in the real world social context, social affiliation can be achieved by means of human mimicry and by shared values and trust among group members. This research will consider the possibility that social affiliation needs also exist in online communities, and that 
real world social affiliation behaviours such as human mimicry and shared values, are what compel people to share large quantities of personal information about themselves online. This research will examine human behaviours in only one of a potentially unlimited number of online situations or contexts. Human behaviour within Facebook, a popular social networking site will be studied in this research.

\section{Value of research}

There has been frequent discussion in the literature about social networking and its impact upon society. While much as been said about issues such as online privacy and the widespread evidence of risky online behaviours and its potential consequences, very little is known about why human beings actually behave in such a way. Understanding these behaviours will aid companies in their attempts to engage with their customers online, to better understand their needs and to provide products and service that meet those needs. It will assist them in building trust among their customers both in the real world and online. It will allow them to attract new customers who share their values, and to gain information from customers that allow them to provide an online community that meets their needs.

\section{Literature review}

\section{Definition of social networking}

Social Networking is best defined as social networking services that assist with the building of online social relationships, sharing of ideas and hobbies as well as a way to connect with friends in a completely interactive environment where the user generates the content (Palvia \& Pancaro, 2010). A further definition states that a social networking site is a site with three components: the ability for members to create profiles, display listings of their own friends for view by others and the ability to connect with others and their friends (Boyd \& Ellison, 2007). A similar definition states that the aim of social networking websites is to facilitate social interaction among members by allowing them to interactively share information, have discussions and arrange for events and functions (Luo, 2010). A Social Networking Service (SNS) offers members: the opportunity to create public or semi public profiles; the functionality to display listings of other users in their networks; and the ability to view and connect with those in their own networks and well as with others in the networks of their friends (Luo, 2010). Extensions of social networking are professional online networks like LinkedIn, or multimedia networking services like YouTube, which appeal to individuals and 
business users (Palvia \& Pancaro, 2010). A final definition of social networking services is that they run in a Web 2.0 environment. Web 2.0 can be defined as the way the internet is used, and in particular demonstrates the following: interactivity, collaboration, information sharing and user generated content (Wade, 2009). The key components in all of these definitions are user generated content, the functionality to create online profiles and to list friends. Social networking sites also allow members to connect to others not already in one's network and the ability to share information online. Due to the open nature of social networks there may be concerns for personal privacy online.

\section{Definition of risky online behaviour}

The literature abounds with examples of what can be construed as risky online behaviour.

There is evidence that large volumes of inappropriate information are posted online on social networking sites like Facebook (Nosko, Wood, \& Molema, 2010). Four hundred randomly selected Facebook profiles were analysed with a view to understanding what information was disclosed online. The type of information appearing in these profiles was matched against a comprehensive checklist of the type of information that is available on Facebook. While there was evidence of large scale disclosure of information by many people that could stigmatise the individual, or information of a very personal or highly sensitive nature, there was evidence of other people who did not reveal this type of information (Nosko, et al., 2010). This research indicated that people who were in search of relationships took the greatest risks online, whereas with increasing age, individuals took lesser risks online (Nosko, et al., 2010). Privacy concerns were found not to impact on the likelihood of university students joining Facebook and revealing considerable amounts of personal information about themselves online (Acquisti \& Gross, 2006). Risky online behaviours included posting information on age, location, sexual preferences, telephone numbers, beliefs, photographs and inappropriate content (Williams \& Merten, 2008). People post information on political points of view and beliefs (Wills \& Reeves, 2009), and posting comments they would not like their faculty, future employers and patients to see (Cain, Scott, $\&$ Akers, 2009). The writing of derisive comments about superiors, photos displaying drunkenness and drug abuse, or wearing skimpy or suggestive clothing are risky behaviours that could cause regrets later on in life (Kornblum \& Marklein, 2006). This is a mere sample of a vast range of online behaviours that could be construed as being risky. The more important question to ask is around the consequences of taking these risks. Prior to examining the consequences of risky online behaviour, the question of online privacy will be considered. 


\section{Privacy issues}

There has been much written in the literature around the lack of privacy in social networking sites like Facebook. One of the main problems with social networking sites is that they create an illusion of privacy (Barnes, 2006). In research conducted in 2006, adolescents seemed to lack awareness that Facebook is a public forum, and even though users wanted to keep certain information private, they were unaware that future employers, universities and others could view this information (Barnes, 2006). Other research demonstrated that adolescents are unconcerned with privacy on the web. Adolescents don't appear to mind if their personal information is used by others. They feel safe sharing information online (Gray \& Christiansen, 2009). Pre-teens and early teens were more likely to take steps to protect their privacy if they viewed online privacy as being important and if they believed in their own ability to protect themselves (Chai, Bagchi-Sen, Morrell, Rao, \& Upadhyaya, 2009). Others have looked at ways to configure privacy settings in Facebook and have reported that where settings can be configured in different places, the least secure setting becomes the default. This makes users vulnerable (Collins, 2010). It was also found that in a sample of the most popular social networking sites including Facebook that none of them complied with all 12 principles of the New Zealand Privacy Act of 1993 (Hooper \& Evans, 2009).

They also found that SNS users may be unaware of the risks associated with interacting on social networking sites, or they choose to ignore the risks as a result of peer pressure (Hooper \& Evans, 2009). Public concern about privacy has led Facebook to review its privacy systems. One of the unresolved issues is who owns the data while the user is a member and after the user has left a social network provider (Palvia \& Pancaro, 2010). Centrally located, this data can be mined for targeted advertising. Users have limited control over their privacy settings. So while there are benefits to social networking that can be enjoyed, one needs to protect one's privacy online by being aware that "private" information may be made available to third parties (Palvia \& Pancaro, 2010). There is now more of an awareness of the issues surrounding online privacy, but this still does not prevent users sharing information online (Mital, Israel, \& Agarwal, 2010). Social networking websites allow for information exchange and information disclosure. This is mediated by trust, as there is a general awareness and knowledge of the privacy issues involved in engaging online on social networks (Mital, et al., 2010). One can conclude then, that Facebook does not guarantee the privacy of its members and perhaps it is in the hands of users to make choices about what content to reveal about them online. Of interest in the literature studied thus far is that there 
are those who are concerned with their own privacy online, and there are also those who are not. Yet, people continue to use Facebook in spite of their fears. Evidence of this is the growth in Facebook's membership. Facebook's membership exceeded the 500 million member mark in 2010 after having been founded only 6 years previously (Wortham, 2010).

\section{Potential consequences of risky online behaviour}

Given that the internet and social networking services are very public by nature, what, according to the literature might be the consequences of risky online behaviour. Risks include potential identity-theft, stalking and embarrassment (Boyd \& Hargittai, 2010) and (Gross \& Acquisti, 2005). Disclosure of inappropriate information can result in unintended consequences for a SNS user (Dwyer, Hiltz, \& Passerini, 2007). Posting of inappropriate content online may result in employment applications being rejected (Cain, et al., 2009) and (Elzweig \& Peeples, 2009). Managers may wish to investigate potential recruits for a role by accessing their information from social networking sites, with or without permission (Elzweig \& Peeples, 2009). Surveys indicate that a significant number of managers use social networking sites to screen job candidates and in $34 \%$ of the cases information discovered online resulted in the candidate not being employed. Users often do not read Facebook's "terms of use" section where there is a disclaimer protecting Facebook in the event that security is breached. Users are also warned that information is posted at the user's risk (Elzweig \& Peeples, 2009). It is also possible that an employer, who does not check for publically available information on Facebook, may be at risk of making a poor recruitment decision (Elzweig \& Peeples, 2009). Another issue with gleaning information from social networking sites is the accuracy of that information, and the manager must take steps to ensure that it is accurate. Job candidates and employees need to be advised if employers intend using SNS's as part of recruitment or retention exercises (Elzweig \& Peeples, 2009).

Private information can be mined for targeted advertising (Palvia \& Pancaro, 2010). A wealth of information is made available online by users and this information is easily mined by marketing companies. Information can easily be retrieved online about user preferences, opinions, choices and decision processes that would otherwise be very costly to uncover (Preibusch, Hoser, Gürses, \& Berendt, 2007). It is also an easy process for political parties to extract political preferences of users without them being aware (Wills \& Reeves, 2009).There are also issues around stalking and sexual predators, because users post location and contact information online making it easy for them to be tracked down by these offenders in the real 
world (Williams \& Merten, 2008). Information gleaned by marketers from SNS is more subjective and complete than information gleaned by other means (Stutzman, 2006). This information reveals more about a person's personality because profiles can contain information of a highly personal nature including photos, political views and sexual orientation (Stutzman, 2006). Users publish a lot of personal information about themselves online including location information (Stutzman, 2006).

These issues might not be as serious if membership of SNS was limited to a few members, but because of the huge growth of the internet and social networks these consequence become a serious problem.

How big an issue is this really? Growth in popularity of SNS

Given the fundamental human need to belong, to be accepted and appreciated by others, humans continually interact with each other socially in the real world (Baumeister \& Leary, 1995) as will be seen in the next section. As a result of this fundamental need, it comes as no surprise that when SNS offered a form of online socializing, they became very popular. Despite the risks, social networking sites are increasing in popularity with $73 \%$ of all American adults having a social networking account, and internet usage among American adults has increase from 67\% in 2005 to $79 \%$ in 2009 (Baughman, 2010). A further milestone in the popularity of social networking was reached in 2010 when Facebook membership figures exceeded the 500 million mark (Wortham, 2010).

The sense of online community that reflects communities in the real world

One of the primary focuses of this research is to discover whether there is a sense of online community that reflects the sense of community that exists among social groups in the real world. This assumption, based on the literature pertaining to real world social groups is considered important to this research.

Older adolescents who valued their peer group membership and felt a sense of positive collective self-esteem within their groups, used SNS as a way of communicating with their peers online (Barker, 2009). Others who experienced negative collective self-esteem in their group membership, sought to use SNS as a way of communicating with others who are not in their peer group, as a way of gaining social compensation (Barker, 2009). In other theoretical research, it was found that a significant sense of community exists online, but that the major factor for continued usage of social networking sites is user satisfaction (Zhang, 2010). 
However the sense of community will impact upon usage by producing user satisfaction (Zhang, 2010). Online community members engage with each other because of their own motivations, but also as a result of social processes. Their behaviour of engaging with an online community is the result of their intention to participate online, which is driven mainly by their social identity and group norms (Zhou, 2011). It was found in research carried out in the Asia-Pacific region that online behaviours reflected the behaviours and beliefs of people in different geographic locations in the real world (Hjorth, 2009). The socio-cultural, ideological and political aspects of each region are reflected in behaviours of those people on social networking sites (Hjorth, 2009). The use of web 2.0 has grown significantly resulting in people of all age groups and professions using social networking sites. The growth of SNS is so great that it is almost a cultural norm among some groupings to have an SNS account. In effect those who do not have a SNS account may be excluded from the group in some social circles (Hjorth, 2009). It was found that as users engaged with other group members online their SNS behaviours changed. Another discovery was that users who are online group leaders determine the acceptable practices for the online group, and other members of the group conformed to these practices (Hjorth, 2009).

An empirical study was carried out to find out what factors contribute to the success of online communities. The study translates terminology used to explain real world group dynamics into a social networking context. The study found that factors like structure, cohesion, and centrality of networks as well a core group are important to the success of online communities formed with a purpose in mind (Toral, Martínez-Torres, Barrero, \& Cortés, 2009). This study demonstrated that there should always be a core group of members who hold the group together. There will also be some individuals who are more connected or networked than others. There will also be loose ties to those members with specialist skills or have something of value to contribute to the group. Another challenge facing online communities is to maintain a minimum number of contributing members (Toral, et al., 2009). Other research demonstrates that many parallels exist between online and off line communities, and there is also evidence that online social networks actually enhance relationships created in the real world, by allowing people to maintain contact online, no matter what their geographic location, so they are not a replacement for real world socialisation (Ellison, Steinfield, \& Lampe, 2007). It is possible to model the strength of online friendships as a predictor of behaviours on social networking sites. Social networking sites are designed in such a way that they facilitate the creation of communities and ensure 
their continuity over time. This is made possible by the ease of which information can be communicated and shared online by members of these communities (Xiang, Neville, \& Rogati, 2010).

Now that risky online behaviours and their potential consequences have been specified, and the existence of an online sense of community has been determined, it is time to begin looking for solutions in the literature. As mentioned in the introduction, attention will now be directed at the literature of Psychology and Sociology in the hope that answers to real world problems around the need to belong and to be accepted, may shed some light on online communities such as Facebook and other online forums.

\section{The need to belong as a driver of human behaviour}

Fundamental to the emotional health and wellbeing of humans is the powerful drive to belong (Baumeister \& Leary, 1995) and this may provide an understanding of human behaviour never before attained (Baumeister \& Leary, 1995). Belonging to groups is important to our evolution and our survival as human beings. (Ridley, 1997) p6 says: "Society evolved as part of our nature. To understand it we must look at the instincts for creating and exploiting social bonds". One of the reasons for the ecological survival of human beings is an ingrained instinct for socialisation (Ridley, 1997). Human beings were not designed to work in isolation, and social ties are important to survival (Ridley, 1997). This need to belong is a drive to build and keep a minimum number of positive, meaningful, and lasting interpersonal relationships and is vital to human existence. Forming of friendships should be easy and there should be an unwillingness to end these friendships (Baumeister \& Leary, 1995). A significant amount of thought and energy is committed by people to interpersonal activities (Baumeister \& Leary, 1995). There are different goals among different ethnic groups for acceptance and belonging, but the ultimate outcome is the need to belong (Bergsieker, Shelton, \& Richeson, 2010).

Perceived changes, whether real or imaginary to one's sense of belongingness, will result in either positive or negative emotional responses (Baumeister \& Leary, 1995). 
Social exclusion has been shown to lead to non-conscious mimicry as a way of building rapport and as a mechanism to deal with the threat to the need to belong (Lakin, Chartrand, \& Arkin, 2008). This drive to be accepted is so strong that when a person is excluded from the in-group, they may unconsciously mimic another member of the in-group as a way of getting re-admitted to the group (Lakin, et al., 2008). Mimicry is a by-product of social interaction with a person one likes, in an unconscious effort to gain approval and acceptance (van Baaren, Janssen, Chartrand, \& Dijksterhuis, 2009). The body language, tone of voice, facial expression and gestures of the person from whom approval is sought is mimicked without the awareness of the mimicker (van Baaren, et al., 2009). It has been theorised that at an unconscious level, mimicry connects people and assists them in forming bonds, but in the event a person does not feel drawn to another person there in an unconscious effort not to mimic that person (van Baaren, et al., 2009). If a person construes themselves as being different from others, they may mimic others to become more connected with them. Research conducted between strangers showed that mimicking behaviour changed the way people engage with and perceive others, and that the mimicked person feels similar and positive towards the mimicker (van Baaren, et al., 2009).

Mimicking behaviour occurs when there is a need to socialise and not when the person feels over socialised. Nevertheless, the decision to mimic or not to mimic is non-conscious (Gabriel, Kawakami, Bartak, Kang, \& Mann, 2010). Humans of all ages avoid ostracism and rejection and use mimicry as a way of a way of gaining acceptance. This behaviour has also been found in children (Over \& Carpenter, 2009). They found that children viewed a thirdparty being excluded (a video showing a shape being excluded by other shapes) lead to behavioural changes by the children (Over \& Carpenter, 2009).

Experiments found in a study comparing the brains of people being mimicked compared to the brains of those who were not, revealed that those areas of the brain responsible for emotion and reward processing were activated in those people who had been mimicked (Kühn, et al., 2009). In stressful situations a hormone called cortisol is secreted by the salivary glands. In an experiment to measure cortisol levels of people with a need to belong in a social situation, some of the subjects were mimicked by another person during their interaction. The other subjects were not mimicked in a similar social engagement. At the 
time, cortisol levels appeared to be unchanged, but at some point immediately after the social exchanges, the cortisol levels (and associated stress levels) were elevated in the non-imitated individuals. This demonstrates the importance of mimicry in developing meaningful and persisting relationships and creating a sense of belongingness (Kouzakova, van Baaren, \& van Knippenberg, 2010). One of the fundamental needs of humans is to be able to build and maintain social relationships that are meaningful (Cialdini \& Goldstein, 2004). The more we like a person, the more we are likely to consciously engage in behaviour that will meet with their approval, and lead to acceptance by them (Cialdini \& Goldstein, 2004). However, we also mimic the behaviour of people that we like at a subconscious level with a view to being accepted by them. This behaviour is not at a conscious level and involves mimicking, for example, the body posture, hand gestures, facial expressions and voice of the person we want to gain the approval of (Cialdini \& Goldstein, 2004).

Social interactions driven by the individual's need to belong are enriched when the individual is mimicked by others. However, in a social situation, when an individual is not mimicked, the need to belong is heightened to the extent that the individual compensates by strengthening the bond between other loved ones (Kouzakova, Karremans, van Baaren, \& Knippenberg, 2010). This was measured by means of a questionnaire containing two questions on how the participants viewed their personal relationships. The test was administered immediately following an activity session where people were either mimicked or not (Kouzakova, Karremans, et al., 2010). While belongingness and conformity to the views of others contributes to a person's self esteem, it appears that as long as a person already has a strong sense of belonging, the need to live by beliefs and views shared by others is not as important to self-esteem (Gailliot \& Baumeister, 2007). So where a person does not belong, conforming to the values and beliefs of others becomes more important (Gailliot \& Baumeister, 2007).

\section{The role of value congruence as a way of gaining social affiliation}

Let us consider Caziers findings that the tendency to divulge more information online on social networks is related to value congruence (Cazier, Shao, \& Louis, 2007). Let us first examine value congruence in an offline context to gain a better understanding of the term. The most important factor in improving the perception of an organisation by its internal and external stakeholders is value congruence (Pirson \& Malhotra, 2008). Research was conducted to find out what matters most to different stakeholders of an organisation. Factors 
studied included generosity, transparency, the skills of management and value congruence as they related to various stakeholders of the business including investors, clients, staff and suppliers (Pirson \& Malhotra, 2008). Even though value congruence was shown to be more important to employees it was clear that all stakeholder groups seek to deal with organisations that reflect their own values (Pirson \& Malhotra, 2008). So there appears to be a drive for people to belong or associate with a group that is in alignment with one's personal values (Posner, 2010).

In the real world, value congruence seems to improve with time. It was found that value congruence among managers coupled with an organisation's espousal of clear values could contribute to job satisfaction, motivation and the reduction of stress, on the job. Over time, managers experienced more alignment of their personal values, with clearly stated organisational values, resulting in the strengthening of the bond with their organisations (Posner, 2010). Some researchers do not believe in the importance of value congruence (Suar $\&$ Khuntia, 2010). Value congruence or the matching together of organisational and personal values was found to be higher in private sector firms than in government departments. It was also found that personal values are more effective in eradicating unethical practises than value congruence itself (Suar \& Khuntia, 2010). But there is evidence that in the real world, value congruence influences how various stakeholders perceive a company (Pirson \& Malhotra, 2008). What of trust in the world of e-business? When the values espoused by an organisation match the values of the customer, a situation of value congruence exists between the customer and the business (Cazier, et al., 2007). This value congruence in e-commerce gives rise to increased trust of the business by the customer, which in turn leads to the customer being prepared to divulge more information about him or her. In fact value congruence in itself may be more effective at getting clients to reveal more about themselves than trust itself (Cazier, et al., 2007). Trust is described by (Caldwell, Davids, \& Devine, 2009) p.104 as "Trust ultimately, must rise to the level of a behaviour that demonstrates the degree to which each individual is personally willing to relinquish control to the party being trusted".

Translated into an online context this could logically point to the relinquishing of personal information online to other trusted parties. It can be argued on this basis that value congruence in the social networking context is a likely reason for the risky online behaviour of revealing too much information online. The evidence presented in this literature review 
indicates that the value congruence experienced in the real world is reflected online in the ecommerce context.

\section{Perceived safety in belonging to online communities lessens the need for personal privacy}

There are those who believe that it is the sense of belonging to an online community that drives risky online behaviour. Research has been carried out that demonstrates the sharing and seeking of information may be driven by those who already experience a sense of community and belonging (Park, Konana, Gu, \& Man Leung, 2010). In research carried out on an online community of investment professionals in South Korea it was decided that behaviours reflected in these communities were the intention to seek information and the intention to share information (Park, et al., 2010). Six factors that contributed to the intention to seek or share information were evaluated. Two of these factors were social factors. There are those members of virtual communities who share information with a view to improve their reputation within the community. There is also an associated reward for this type of behaviour in terms of social capital where there may be a financial reward (Park, et al., 2010). Members of the online community are also driven by a sense of belonging making them more likely to share information with other community members, and more trusting of the information they seek from others. The authors concede that these behaviours are applicable to other virtual communities including online social networks where people seek and share information interactively (Park, et al., 2010).

\section{Online disinhibition effect and social boundaries}

Online users display a continuum of behaviours from the extremes of being completely disinhibited through to behaviour that is completely guarded and distrusting, and these behaviours vary depending on the online situations being experienced by the user (Suler, 2004). For the purpose of this research, three types of online disinhibition will be considered. There is "dissociative anonymity" where a person can engage anonymously with others online (Suler, 2004). While Facebook requires members to create profiles, many create profiles with pseudonyms to protect their anonymity online. This gives them the freedom to make public what they wouldn't reveal in real life and justifying their behaviour by denying that their online image is what they are like in the real world (Suler, 2004).

The next type is "invisibility” Invisibility can increase the disinhibition effect because users can ignore the impact of what they are saying under the cloak of anonymity as there is no body language or other non-verbal communication in text language that indicates how the message is being received (Suler, 2004). The final type of interest to this research is 
"asynchronicity"where people do not communicate with each other in real time. This allows a person to post a comment and flee from the consequences (Suler, 2004)" These behaviours are grounded in each person's psychological "self boundary". In the offline world it is easier to define this self-boundary because of the awareness of one's own physical body, thoughts and feelings and their perception of the outside world using the five senses. These five senses are not utilised in the online context as much as they are in face-to-face encounters in the real world (Suler, 2004). Self boundary in the online context becomes blurred and it is more difficult for a person to distinguish between the inner person and the outer person, resulting in information that would normally be hidden, being displayed in the open. The converse would also be true when this erosion of boundaries results in users becoming extremely guarded and anxious about sharing personal information online (Suler, 2004). The information here highlights the importance of the non-verbal components to effective communication and also the fact that people behave differently in different online contexts. The belief that a person either engages in risky online behaviour, or refrains from doing so, may be incorrect. More likely is the possibility that a person engages in some online behaviour that is risky and other behaviours that are not, depending on the online environment being experienced at the time.

\section{Conclusion of literature review}

The literature review confirms that people of all ages have a tendency to engage in risky online behaviour at times. The consequences of such risky behaviour can range from embarrassment, to sexual predation, to identity theft and could potentially impact negatively on the life of the social networking member. In many cases this is due to the illusion of being private, due to sheer ignorance on how to effectively manage one's online privacy settings, or simply not caring. However, the way in which privacy is perceived may be changing and could form the foundation of further research. Areas such as risky online behaviour, privacy and trust have been researched intensively, and despite growing awareness of the risks, people still persist in posting too much and often inappropriate information about themselves online. There is also evidence in the literature of the enormous growth of online social networking, which compounds the problem.

However, not much empirical research has been carried out to understand why people persist in engaging in risky online behaviour, despite an awareness of the risks. The literature indicates, however, that there is a sense of community online that reflects the same sense of community that exists in groups in the real world. The literature demonstrates how powerful the human need for affiliation can be, and the extent to which people will go if this need is 
not met, or they have been ostracized from their group. It also reveals how human mimicry as an unconscious behaviour, is a means by which humans are accepted by others and included in their groups. One can reasonably assume that belongingness and mimicry in the real world is replicated online in the parallel communities that exist in there.

The role of value congruence also needs to be considered further. Sharing the values of a group may make it easier to be accepted and included both in the real and online world, and could lead to misguided trust and the tendency to reveal too much online. In this literature review it was demonstrated that certain behaviours manifest themselves in real world groupings, and that much of this behaviour is driven by the need to belong. This social for affiliation has been shown to be a reason for the survival and evolution of mankind, and that this drive is hardwired into humans at an instinctual level, ensuring their survival.

Mimicry and value congruence have been shown to promote acceptance by groups in the real world. Value congruence also has been show to improve trust, but also to cause people to reveal more information about them online. The literature has revealed parallels between online communities and the social groups in the real world, and it has been shown how value congruence can lead to acceptance in online and real world communities. Given that need to belong exists online as it does in real world, and given that value congruence as a means of building trust both off and online has been demonstrated, it would lead to the logical conclusion that these activities are a way for people to be accepted by online communities, and could be the reason why many people publish too much information about themselves online. These facts coupled with unconscious human mimicry at an instinctual level, as a way of gaining acceptance in social groupings in the real world, a case could be made for explaining the risky online behaviour despite an awareness of the consequences. However, a caveat exists. It is clear that people behave differently depending on the online context in which they are engaging in, and there is a possibility that online communities are beginning to erode the self-boundaries of people who have always been dependent on the five senses to perceive self and the world.

\section{Assumptions and hypotheses}

Based on the literature review, the following assumptions were made:

1. In their attempts to gain social affiliation in an online community people exhibit behaviours similar to those used in the real world. 
2. People's online behaviour on social networking sites reflects social affiliation behaviour in the real world.

These assumptions gave rise to 3 hypotheses that were tested in this research. The hypotheses tested are listed below. The interview/survey questions used to test these hypotheses appear in Chapter 9.

H1: Humans mimic online behaviours including risky behaviours to gain acceptance in online communities

$\mathrm{H} 2$ : The need for personal safety online is secondary to the need for social affiliation

H3: Humans reflect the values of their friends on social networks to gain their approval

\section{Theoretical framework}

Research can be qualitative or quantitative in nature, or both. Some schools of thought believe that a combined approach will be best. These methods are born out of research philosophies which very often contradict each other. The research carried out for this paper, will be qualitative in nature with a small component of quantitative analysis. Due to the qualitative component of this research, it could be argued that value will be gained by the researcher engaging subjectively with the research objects and using his own beliefs and experience to make sense of and interpret the data. The research design will depend on the philosophical approach to be followed. A number of philosophies will be considered with a view to deciding upon an appropriate methodology to follow, given that a mix of qualitative and quantitative analysis will be used in carrying out this research. A mixed philosophical approach is recommended as each philosophy in its own right has advantages and disadvantages and applicability to the proposed research. A combination of philosophies is considered likely give most credence to the results of this research.

The first philosophy that will be considered is post positivism. Post positivists believe that observation is biased because it is theory-laden and can be challenged (Onwuegbuzie, Johnson, \& Collins, 2009). Observers are also viewed as being unable to make purely objective decisions due to their own beliefs and values. To overcome this lack of objectivity, post positivists employ triangulation techniques to confirm their findings and they also make use of probabilities in their analyses. While the focus of post positivism is on quantitative research, inferential statistics (inductive processes) are often used when making 
generalizations (Onwuegbuzie, et al., 2009). Post positivism like positivism is effective as a tool to observe, measure and explain a phenomenon (Hovorka \& Lee, 2010). The use of triangulation techniques to counteract researcher bias makes this philosophy appropriate to the research in question. As will be seen, Likert Scale ordinal data will be collected by means of surveys and these findings will be triangulated and supplemented with the results of interview data that has been subjected to a qualitative content analysis.

The researcher will engage face to face with his interview subjects and will be drawing on his own belief sets, values, education and experience when interpreting the data. This implies that his findings may not be replicated by another researcher with a different mix of experience, education and beliefs. A broad group of philosophies, Interpretivism, recognises this fact and assumes the researcher and reality are intertwined. It is based on the view that the researchers' understanding of the world, and the way that they interpret the data, is built upon by their experience in life and that the two cannot be separated. The methodology followed by this research is hermeneutic and phenomenological in nature (Butler, 1998). Interpretivism is grounded in an ontology that views all observation as being laden with values and theory and that the investigation of social systems cannot be measured by means of cold and detached objective truth (Leitch, 2003). Interpretivism is effective as a tool to gaining an understanding of a social system (Hovorka \& Lee, 2010). This philosophy is considered to be appropriate to this research as a large component of this research is around social behavioural issues and it is not possible for the researcher to be completely detached and objective in this context.

Constructivism falls within the umbrella of Interpretivism and is as such concerned with human meanings and experiences. The reasoning style is inductive and there is an emphasis on qualitative research. People make sense of their world by creating constructions and meanings, and these are measured by constructivist research. The two approaches to constructivism focus on individual or social constructions. Grounded constructivism recognises that the observer creates the data and analysis through engagement with the observed. Data is therefore not intended to be objective. The researchers life experiences and beliefs form the data through interaction with the participants and this makes the data realistic, and opens up new avenues for investigation (Onwuegbuzie, et al., 2009). Qualitative research has its roots in constructivism and human researchers construct their information on the basis of their interaction with the people they are studying (Caelli, Ray, \& Mill, 2008). 
This philosophy will be reflected in this research to some extent through Interpretivism, although the intention will be remove some of the bias through triangulation. Triangulation will add some credence to the findings but it is the intention of this research that such data is subject to the interpretation of the interviewer.

\section{Comparing and Contrasting the Philosophies:}

The research philosophies considered here fall into one of two broad umbrella categories of research philosophy - positivism and interpretivism. There are variations on both. At the one extreme, the observer is separate from the observed and is separate from a reality which can be determined accurately. At the other, it is acknowledged that the observer and the observed are interlinked and that the views of the observer are not strictly objective, but that the life experiences of the researcher adds value to the understanding of the data. There has been a call for mixed philosophical approaches to research, and that the dogmas and words used by each philosopy to discredit the other, no longer serve a useful purpose (Weber, 2004). It seems that there is a place for all research philosophies with some philosophies suited to certain research types and not to others. There appears to be some wisdom in the call for a mixed approach to research (Onwuegbuzie, et al., 2009).

This research will be based on a literature review and a mixture of qualitative and quantitative analysis.

Quantitative analysis, using surveys and descriptive statistics will be useful in measuring the level of agreement or disagreement with a series of statements on a 5 point Likert scale in an online survey. The qualitative component of this research involves the content analysis of five open ended questions accompanying each group of Likert Scale statements in an attempt to gain additional clarity on the Likert Scale responses. Additionally a series of face to face interviews will be carried out in order to seek further clarity on identified issues. These methods are expected to confirm and enrich the findings of the survey and to provide additional answers to the questions still unanswered by the survey.

Due to this three pronged approach of a literature review, a quantitative Likert scale survey, the use of qualitative open ended survey questions and qualitative interviews, it is believed that the results of this research will be seen to be valid due to the triangulation of results. From a philosophical point of view, a mixture of post-positivism and constructivism will be employed in this research. While there is no interaction between the researcher and the 
respondent in an online survey, the measured results are subject to the interpretation and bias of the researcher, making it necessary to employ triangulation techniques to limit the level of subjectivity in the research. This is in line with the view of post-positivism and it is on this basis that the research will be designed. Furthermore it is accepted that with the interview process, the researcher will rely on his experience and knowledge to interpret the results in a content analysis. So the interview process will be governed by a constructivist philosophy.

\section{Research design and methodology}

\subsection{Literature Review:}

As a result of the Literature Review, consideration was given to the research topic, the hypotheses and research methodology. These were reviewed and finalised. On conclusion of the literature review, approval was sought and granted by the Human Ethics Committee of the Victoria University School of Information Management, to carry out this research.

\subsection{Online Survey:}

Survey sample: All of the Facebook friends of the researcher were emailed from within Facebook, with a link to a confidential survey. The survey was built using Qualtrics. The sample size was 64 surveys out of 105 invitations to participate. Of 64 surveys attempted, 60 were completed. The decision to send the surveys out with a 10 day deadline was motivated by the expectation that the majority of completed surveys would be returned by respondents who are fairly regular users of Facebook.

Type of Survey: The survey used was a five-point Likert Scale. Respondents were asked to rate 14 questions / statements according to a scale from "strongly agree" to "strongly disagree". Additionally, there were 5 freeform questions designed to gain more clarity on the motivations for the responses to each group of Likert Scale questions.

Design of Survey Questions: The literature demonstrated the ways in which humans behave, even at subconscious levels, to gain and maintain their social affiliations in the real world. The questions in the survey below were designed to find out if these reported real world social affiliation behaviours, also occur in online communities. Each respondent was asked to express agreement or disagreement with a number of statements describing online situations that replicated real world group affiliation behaviours. This assisted the researcher in establishing whether the respondents online behaviours, reflect what is known to be true 
about their social affiliation behaviours in the real world. The intention was to demonstrate that online social affiliation behaviours are the reason behind risky online behaviours and the tendency to post large quantities of personal and at times inappropriate information about themselves online.

\begin{tabular}{|c|c|c|c|c|c|c|}
\hline \multicolumn{2}{|r|}{ Online Survey Questions } & \multicolumn{5}{|c|}{$\begin{array}{c}\text { Disagree }<> \\
\text { Agree }\end{array}$} \\
\hline & \multicolumn{6}{|l|}{ SENSE OF ONLINE COMMUNITY } \\
\hline 1 & $\begin{array}{l}\text { I experience negative emotions when somebody online turns down } \\
\text { my request for friendship. }\end{array}$ & 1 & 2 & 3 & 4 & 5 \\
\hline 2 & $\begin{array}{l}\text { I feel a sense of community, inclusion and belonging among my } \\
\text { online friends. }\end{array}$ & 1 & 2 & 3 & 4 & 5 \\
\hline 3 & $\begin{array}{l}\text { There is an expectation among my circle of friends that I have an } \\
\text { account with Facebook or one of the other social networks. }\end{array}$ & 1 & 2 & 3 & 4 & 5 \\
\hline 4 & $\begin{array}{l}\text { I felt left out when all of my friends had Facebook accounts and I } \\
\text { didn't. }\end{array}$ & 1 & 2 & 3 & 4 & 5 \\
\hline \multirow[t]{2}{*}{5} & $\begin{array}{l}\text { In your experience, how does your membership of Facebook impact } \\
\text { upon your life? }\end{array}$ & $\begin{array}{l}\mathbf{F} \\
\mathbf{F}\end{array}$ & $\begin{array}{l}\mathbf{R} \\
\mathbf{O}\end{array}$ & $\begin{array}{l}\mathbf{E} \\
\mathbf{R}\end{array}$ & $\begin{array}{l}\mathbf{E} \\
\mathbf{M}\end{array}$ & \\
\hline & HuM & & & & & \\
\hline 1 & $\begin{array}{l}\text { When returning at a later stage to an online discussion I have been } \\
\text { having on Facebook, I sometimes feel embarrassed by my own } \\
\text { comments and / or actions. }\end{array}$ & 1 & 2 & 3 & 4 & 5 \\
\hline 2 & $\begin{array}{l}\text { When entering an online discussion with somebody I like, I tend to } \\
\text { support their point of view. }\end{array}$ & 1 & 2 & 3 & 4 & 5 \\
\hline 3 & $\begin{array}{l}\text { When responding to invitations on Facebook my decisions are } \\
\text { unconscious and reactive, rather than conscious and deliberate. }\end{array}$ & 1 & 2 & 3 & 4 & 5 \\
\hline 4 & $\begin{array}{l}\text { After creating my Facebook profile, I was surprised at how closely it } \\
\text { resembled the profiles of my friends }\end{array}$ & 1 & 2 & 3 & 4 & 5 \\
\hline 5 & $\begin{array}{l}\text { Think of a situation when you changed your language and style when } \\
\text { communicating with somebody else on Facebook. Why do you think } \\
\text { you did this? }\end{array}$ & $\mathbf{F}$ & $\begin{array}{l}\mathbf{R} \\
\mathbf{O}\end{array}$ & $\mathbf{E}$ & $\begin{array}{l}\mathbf{E} \\
\mathbf{M}\end{array}$ & \\
\hline
\end{tabular}




\begin{tabular}{|c|c|c|c|c|c|c|}
\hline & Personal Safety & & & & & \\
\hline 1 & $\begin{array}{l}\text { If there is an expectation among my online friends for me to behave } \\
\text { in ways that contradict my personal beliefs and values, I conform in } \\
\text { an attempt to feel accepted. }\end{array}$ & 1 & 2 & 3 & 4 & 5 \\
\hline 2 & $\begin{array}{l}\text { I am unconcerned about my personal privacy because I have found a } \\
\text { strong sense of acceptance, belonging and friendship online. }\end{array}$ & 1 & 2 & 3 & 4 & 5 \\
\hline 3 & $\begin{array}{l}\text { If I am ostracised by my online friends, I will do whatever it takes for } \\
\text { me to be accepted again. }\end{array}$ & 1 & 2 & 3 & 4 & 5 \\
\hline 4 & $\begin{array}{l}\text { I share controversial information with my online community because } \\
\text { I trust them. }\end{array}$ & 1 & 2 & 3 & 4 & 5 \\
\hline 5 & $\begin{array}{l}\text { In light of what has been said about personal safety and privacy on } \\
\text { Facebook what actions have you taken to protect yourself online? }\end{array}$ & $\begin{array}{l}\mathbf{F} \\
\mathbf{F}\end{array}$ & $\begin{array}{l}\mathbf{R} \\
\mathbf{O}\end{array}$ & $\begin{array}{l}\mathbf{E} \\
\mathbf{R}\end{array}$ & $\begin{array}{l}\mathbf{E} \\
\mathbf{M}\end{array}$ & \\
\hline & VALU & & & & & \\
\hline 1 & $\begin{array}{l}\text { I only buy from companies in the real world and online that reflect } \\
\text { my personal values }\end{array}$ & 1 & 2 & 3 & 4 & 5 \\
\hline 2 & $\begin{array}{l}\text { I only share personal information online with Facebook friends I } \\
\text { trust }\end{array}$ & 1 & 2 & 3 & 4 & 5 \\
\hline 3 & $\begin{array}{l}\text { When sharing personal information online, I always check to see if } \\
\text { the person or company requesting it, truly reflects my values }\end{array}$ & 1 & 2 & 3 & 4 & 5 \\
\hline 4 & $\begin{array}{l}\text { I feel more accepted by my online friends if I reflect their values and } \\
\text { beliefs }\end{array}$ & 1 & 2 & 3 & 4 & 5 \\
\hline 5 & $\begin{array}{l}\text { Think of a time when you revealed significant amount personal } \\
\text { information about yourself online to friends on Facebook. Was this } \\
\text { because you trusted them or was it more to do with the fact that they } \\
\text { share your values? }\end{array}$ & $\begin{array}{l}\mathbf{F} \\
\mathbf{F}\end{array}$ & $\mathbf{R}$ & $\begin{array}{l}\mathbf{E} \\
\mathbf{R}\end{array}$ & $\begin{array}{l}\mathbf{E} \\
\mathbf{M}\end{array}$ & \\
\hline
\end{tabular}




\subsection{Interviews:}

Semi-structured interviews were carried out with eight New Zealand Facebook friends, to triangulate with and supplement information gathered by means of the online surveys. The interviewees were selected according to the following criteria:

- The news feed demonstrated their recent activity on Facebook

- They were all professionals and currently employed

- They were located in Wellington, New Zealand and available to attend a face-to-face interview

- They are all members of Generation X

Twelve potential respondents met all four of the above criteria. Of these, one did not wish to be interviewed and three were not in Wellington at the time of the interviews. This left a total of eight participants who were all interviewed.

\section{Interview Questions}

1. What are the similarities and differences between interacting with others in an online community, and interacting with others in real world groups?

2. In the real world and online, people often change their behaviour depending on who they are speaking with. Describe a situation where this happened to you. Was it a conscious decision on your part to change your communication style, or did you change it without realising it? What motivated your change in your communication style?

3. If you are, or were, a person who only invited people you already knew and trusted to become Facebook friends, do you think you would still need to configure your privacy settings or does this now have lesser importance - please elaborate?

4. In view of the fact that Facebook membership is free, how do you think that Facebook generates revenues and profits? Is that of concern to you? Why or why not?

5. Do you think Facebook is more or less risky than Linkedin. On which site are you prepared to share more personal information any why?

\subsection{Descriptive statistics (Quantitative analysis)}

In view of the fact that survey data were collected using a Likert Scale; the data will be ordinal data rather than interval data. It was initially analysed using descriptive statistics such as tables, bar charts and graphs and of particular interest were the value of the modes for each question. Further analysis was carried out by summing the "strongly agree" and "agree" 
responses into one group, while summing the "strongly disagree" and "disagree" responses into a second group and carrying out comparisons between the data. The graphing tool used was the standard Qualtrics graphing tool.

\subsection{Content analysis (Qualitative analysis)}

In order to triangulate findings of the quantitative analysis carried out above, a qualitative analysis was carried out by means of a series of interviews and freeform survey questions. This was done to verify the findings in the survey and to supplement and/or clarify those findings. Interview and survey data were subjected to a full qualitative content analysis. Comparisons were then drawn between the information produced and the hypotheses, and to consider whether the hypotheses were supported or not. The qualitative analysis tool used for coding and analysing the data was an open source software programme called Weft-QDA

\section{Design Factors}

While the content analysis of the freeform data and the analysis of the Likert Scale data is subject to interpretation by the researcher based on his experience, the research instruments themselves were designed to limit some of the possible bias. The following steps were taken:

- Prior to sending out invitations to participate in the online survey, the survey was tested on a number of work colleagues who were not taking part, to check on possible ambiguity of survey questions.

- There was no contact at all between survey participants and the interviewer, ensuring that the interviewer was unable to influence the answers given by respondents to the questions.

- The Qualtrics Survey software analysed the data and produced the tables and charts without the researcher's intervention.

- The research was designed on the basis of an intensive literature review.

\section{Potential Bias}

- Due to the fact that Facebook friends of the researcher were scattered around the globe, interview participants had to be selected from the Wellington region, meaning that the interviewees did not represent all of the nations involved in this research.

- In the content analysis, the Weft-QDA software allows for data categories to be created for analysis. Each response to a question had to be marked and added to a category (coded) by the researcher. In a case where a comment could fit a number of different categories, the researcher had to exercise his discretion. 
- The interpretation of the graphs produced by the quantitative analysis was dependent on the experience and beliefs of the researcher.

- The interpretation of the freeform survey questions was dependent on the experience and beliefs of the researcher.

While the sample sizes used in this research are too small for making generalizations from, there were some interesting findings and these will be discussed in Chapter 10.

\section{Analysis and Results}

\subsection{Analysis of Survey Data}

The quantitative part of this research involved the administration of an online survey to 105 possible participants, all of whom were Facebook friends of the researcher. Sixty four respondents submitted surveys that were fully or partially completed, and of these, a total of 60 submitted competed surveys. Their responses to a series of statements were measured by means of a forced 5 point Likert Scale. Prior to analyzing these results, let us consider the demographic variables of the surveyed respondents.

\section{Demographic Variables}

Last Modified: 05/20/2011

\section{My gender is?}

\begin{tabular}{|c|l|l|c|c|}
\hline$\#$ & Answer & & Response & $\%$ \\
\hline 1 & Male & & 37 & $60 \%$ \\
\hline 2 & Female & & 25 & $40 \%$ \\
\hline & Total & & 62 & $100 \%$ \\
\hline
\end{tabular}




\section{My place of residence is?}

\begin{tabular}{|c|l|l|c|c|}
\hline$\#$ & Answer & Response & $\%$ \\
\hline 1 & New Zealand & & 38 & $61 \%$ \\
2 & Austraia & & 6 & $10 \%$ \\
3 & South Africa & & 13 & $21 \%$ \\
4 & Europe & USA & 2 & $3 \%$ \\
5 & Other & & 3 & $5 \%$ \\
6 & Total & 0 & $0 \%$ \\
\hline
\end{tabular}

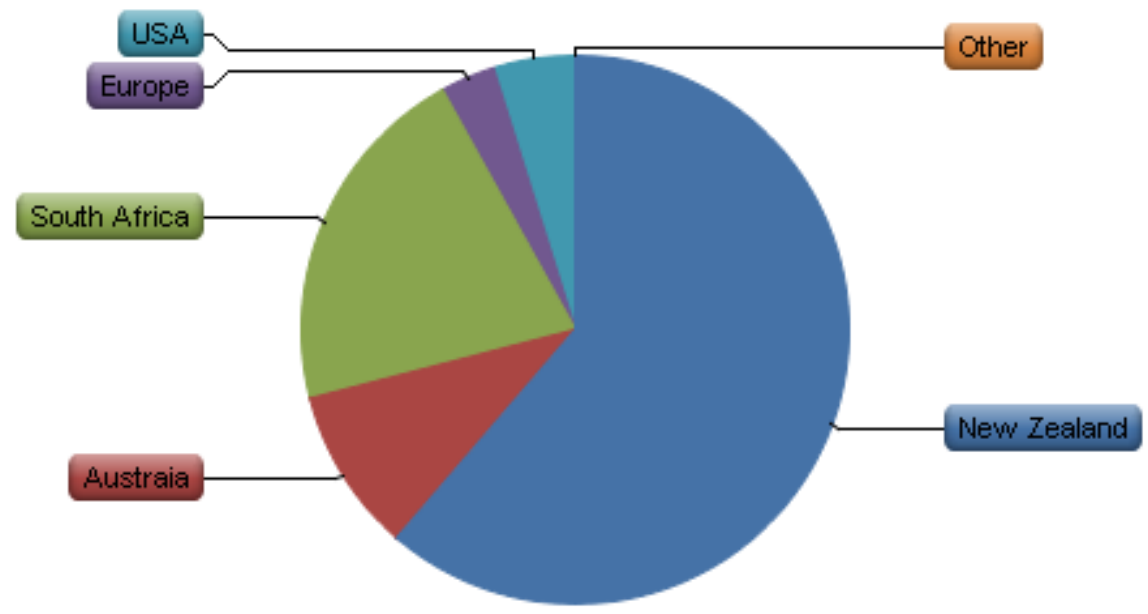




\section{My Generation is?}

\begin{tabular}{|c|c|c|c|}
\hline$\#$ & Answer & Response & $\%$ \\
\hline 1 & $\begin{array}{l}\text { Traditionalists } \\
\text { (pre 1946) }\end{array}$ & 2 & $3 \%$ \\
\hline 2 & $\begin{array}{l}\text { Boomers } \\
(1946-1963)\end{array}$ & 31 & $50 \%$ \\
\hline 3 & $\begin{array}{l}\text { Gen X (1964- } \\
1974)\end{array}$ & 15 & $24 \%$ \\
\hline 4 & $\begin{array}{l}\text { Gen Y (1975- } \\
1990)\end{array}$ & 13 & $21 \%$ \\
\hline 5 & $\begin{array}{l}\text { Millennials } \\
\text { (post 1990) }\end{array}$ & 1 & $2 \%$ \\
\hline & Total & 62 & $100 \%$ \\
\hline
\end{tabular}

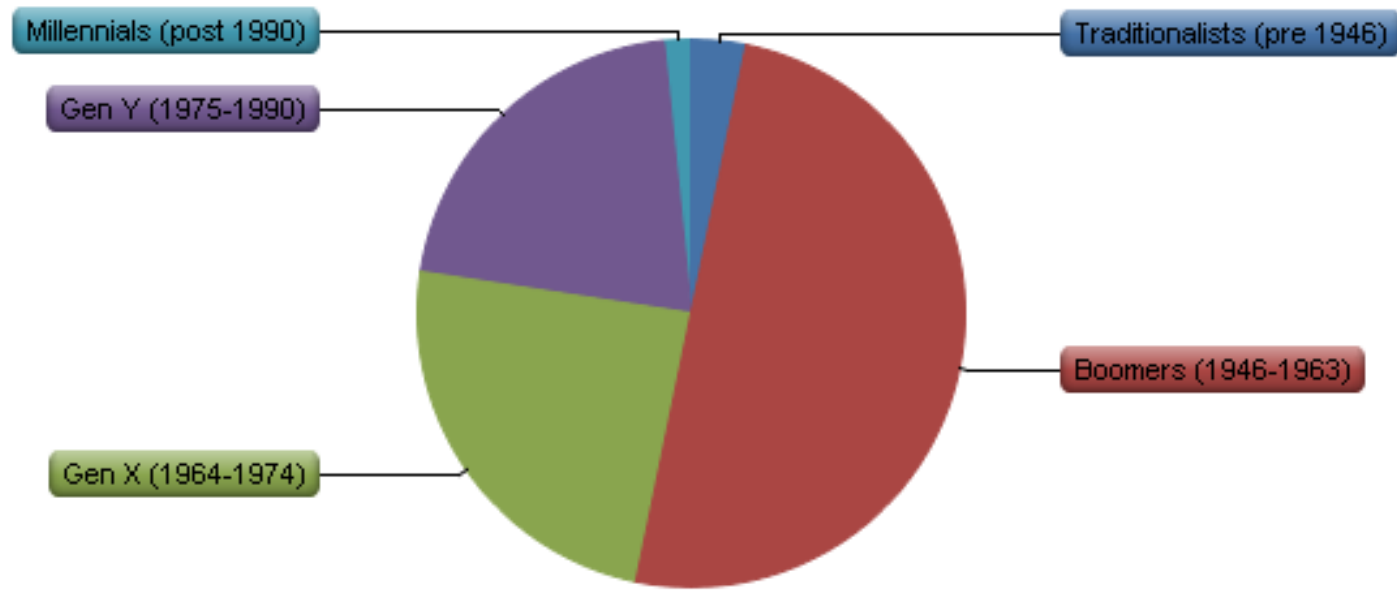

The survey data comprised Likert Scale Questions plus freeform questions. In each case the appropriate Likert Scale results (quantitative analysis) was considered, followed by the results of the content analysis data from the survey freeform questions using the "Weft QDA" (qualitative analysis) tool to code the data. 
The results structure will be:

Likert Scale Question(s)

Survey freeform question relating to the above Likert Question(s)

A separate qualitative analysis of the interview data will appear in the following chapter.

\section{Decisions on which results to use:}

- In cases where either the "agree" and or "strongly agree" categories outweighed the "disagree" and or "strongly disagree" categories, or vice versa, that data was considered in these results.

- In cases where there was no clear majority among those who agreed or disagreed, that data was not considered in this analysis. 


\section{Likert Scale Question 1: I feel a sense of community, inclusion and belonging among my online friends.}

\begin{tabular}{|c|c|c|c|}
\hline$\#$ & Answer & Response & $\%$ \\
\hline 1 & $\begin{array}{l}\text { Strongly } \\
\text { Disagree }\end{array}$ & 0 & $0 \%$ \\
\hline 2 & Disagree & 6 & $10 \%$ \\
\hline 3 & $\begin{array}{l}\text { Neither } \\
\text { Agree nor } \\
\text { Disagree }\end{array}$ & 24 & $39 \%$ \\
\hline 4 & Agree & 31 & $50 \%$ \\
\hline 5 & $\begin{array}{l}\text { Strongly } \\
\text { Agree }\end{array}$ & 1 & $2 \%$ \\
\hline & Total & 62 & $100 \%$ \\
\hline
\end{tabular}

This question was designed to determine whether respondents perceive the existence of an online community.

This result agrees with the literature and indicates that $50 \%$ of the respondents experienced a sense of community and belonging online (Barker, 2009), (Hjorth, 2009), (Zhang, 2010) and (Zhou, 2011). The literature has reported extensively on the need for social affiliation in the real world (Baumeister \& Leary, 1995), (Ridley, 1997), (Lakin, et al., 2008) and (van Baaren, et al., 2009). Of interest to the researcher here is whether online communities are similar to real world groups and that by extension the social affiliation needs experienced in the real world apply equally to online communities.

The qualitative analysis of the free form question pertaining to Likert Scale Question 1 is now considered: 


\section{Freeform Question 1: Impact of Facebook}

This question was designed to understand perceptions of survey participants to Facebook, why they use it and the way it has impacted upon their lives. It was anticipated that by designing the question as openly as possible, some clues as to a sense of online community might emerge. Of the 54 responses received for this question $36(67 \%)$ felt it was an excellent tool for tracking down old friends, building online ties with existing friends and socialising online with family and friends. This result could be interpreted to mean that existing friendships and real world groups like families are being replicated online.

Examples of these responses included:

Question1 [699-816]

Biggest gain is maintaining contact with good friends from my international high school who live all over the world.

Question1 [1776-1881]

I get to keep up with what's going on in my friends lives, especially those who live in other countries

\section{Question1 [3512-3889]}

It allows me to keep in contact with friends and family who live all over the world.

I use Facebook primarily to keep in contact with my friends overseas who I would not be able to keep in contact with otherwise. It is a strong tool for maintaining friendships and seeing what my friends are up to. I often check Facebook multiple times a day to see what my friends are doing.

\section{Question1 [5263-5555]}

I was pleased when an old friend made contact through being on Facebook.

In my experience, Facebook helps me to keep my relationship with my friends. It makes it possible to keep in touch with overseas friends. I check my Facebook at least once a week to see where my friends up to.

Of the 16 respondents who thought that Facebook had a negative impact in terms of time wasting or felt there was no impact at all, 13 conceded that it was a great tool for building online relationships with family and existing and past friends. Yet again these responses point to a replication of real world groups online. Examples of these comments include: 
Question1 [4972-5067]

Not a big impact but I have enjoyed getting into contact with people I have often thought about

Question1 [7387-7475]

It doesn't impact....I have a FB page mainly for keeping in touch with distant relatives

While the question did not specifically ask about the existence of an online community of friends, this message came through very clearly. Only two respondents referred to befriending people they didn't know. $67 \%$ of all respondents demonstrated that they were rebuilding groups online that they are/were part of in the real world. This confirms that online communities of people are created to reflect the communities in the real world. In $67 \%$ of the cases reported in these results, family groupings were being replicated online and groups of old school friends were forming online communities. There was also evidence of real world special interest groupings and affiliations forming online:

Question1 [421-483]

I joined to find a support group for my illness as none in $\mathrm{nz}$.

Question1 [970-1052]

I like to receive news from organisations I am affiliated with eg soccer club, and forest and bird

The results of this freeform question agree with the findings of the Likert Scale data on this topic. The Likert Scale found that $52 \%$ of all respondents agreed, to some extent, in the existence of an online community. The freeform data suggested that a greater figure of $67 \%$ of respondents agree with the concept of an online community. These findings are supported in the literature. It was also found that social networking sites re-enforce the bonds formed in real world groupings (Ellison, et al., 2007). Others have likewise reported the existence of online communities (Barker, 2009), (Zhang, 2010), (Hjorth, 2009) and (Toral, et al., 2009).

The majority of respondents in this survey reported a positive experience with Facebook and this may explain why social networking sites have become so popular worldwide (Baughman, 2010), and (Wortham, 2010). 
The next two Likert Scale questions and the freeform question that follows, consider the possibility of unconscious mimicry as a way of attaining social affiliation in online communities.

\section{Likert Scale Question 2: When returning at a later stage to an online discussion I have been having on Facebook, I sometimes feel embarrassed by my own comments and / or actions.}

\begin{tabular}{|c|c|c|c|}
\hline$\#$ & Answer & Response & $\%$ \\
\hline 1 & $\begin{array}{l}\text { Strongly } \\
\text { Disagree }\end{array}$ & 12 & $19 \%$ \\
\hline 2 & Disagree & 28 & $45 \%$ \\
\hline 3 & $\begin{array}{l}\text { Neither } \\
\text { Agree nor } \\
\text { Disagree }\end{array}$ & 14 & $23 \%$ \\
\hline 4 & Agree & 8 & $13 \%$ \\
\hline 5 & $\begin{array}{l}\text { Strongly } \\
\text { Agree }\end{array}$ & 0 & $0 \%$ \\
\hline & Total & 62 & $100 \%$ \\
\hline
\end{tabular}

This question was designed to establish whether negative or potentially embarrassing information was shared online in a chat or discussion board situation, that a person later regrets after giving those thoughts due consideration. Also of importance was the possibility that such information was posted in response to an online discussion between friends in an unconscious and reactive way rather than in a deliberately thought out fashion. This question was based on research in the real world where unconscious mimicry is a way of achieving social affiliation. Important to note is that the literature agrees that mimicry is an unconscious behaviour as opposed to imitation which is not (Lakin, et al., 2008), (van Baaren, et al., 2009) and (Gabriel, et al., 2010). The objective of this question was to establish the existence of unconscious mimicry online. 
The results here point to the fact that $64 \%$ of the respondents "disagree" or "strongly disagree" that they have ever engaged in the unconscious behaviour discussed above. It should be noted that the behaviour being measured here is only one of an unlimited number of behaviours that could potentially demonstrate human mimicry. To completely discount online mimicry on this basis would not be wise, and this may be an avenue for other researchers to investigate. Suler, (2004) warned that people can swing from being totally disinhibited online in one situation, to being totally guarded in another. For the majority of people in this online context, posting negative comments without thinking was something they are not aware that they might be doing. However, in another online context, their online behaviour might be completely disinhibited and risky (Suler, 2004). So it is possible that the same users surveyed here might engage in mimicry on other social networking sites like Linkedin, perhaps to win approval or acceptance by a prospective employer. 


\section{Likert Scale Question 3: When responding to invitations on Facebook to become friends, my decisions are unconscious and reactive, rather than conscious and deliberate.}

\begin{tabular}{|c|c|c|c|}
\hline$\#$ & Answer & Response & $\%$ \\
\hline 1 & $\begin{array}{l}\text { Strongly } \\
\text { Disagree }\end{array}$ & 15 & $24 \%$ \\
\hline 2 & Disagree & 32 & $52 \%$ \\
\hline 3 & $\begin{array}{l}\text { Neither } \\
\text { Agree nor } \\
\text { Disagree }\end{array}$ & 2 & $3 \%$ \\
\hline 4 & Agree & 9 & $15 \%$ \\
\hline 5 & $\begin{array}{l}\text { Strongly } \\
\text { Agree }\end{array}$ & 4 & $6 \%$ \\
\hline & Total & 62 & $100 \%$ \\
\hline
\end{tabular}

This question once again shows little support for unconscious mimicry online as a way to gain acceptance. While $76 \%$ of the respondents disagreed with the statement, it is in and of itself inadequate evidence to be able to disprove the existence of human mimicry online. We have only considered this in the context of accepting friends on Facebook, but on another social network, these self same respondents might behave in a different manner as was discussed in the literature on online disinhibition (Suler, 2004).

In another context of being invited to join a game or accepting an invitation to support a cause, the same respondents surveyed above might behave in a different way. Their response to those requests may be instinctive or unconscious indicating the use of mimicry to gain acceptance online.

However, this question revealed another issue of importance to the Facebook users in this survey. Viewing this same data from another perspective suggests that in the case of $76 \%$ of 
the respondents, the decision to admit a Facebook friend was clearly a deliberate and well thought out decision, indicating that personal safety is of concern to this group of Facebook users. This issue is reinforced by the results of Likert Scale Question 4, and a more detailed analysis will follow on from that question.

The qualitative analysis of the freeform question relating to the Likert Scale Questions $2 \& 3$ appears below:

\section{Freeform Question 2: Human Mimicry as a predictor of risky online behaviour.}

It is the researcher's experience in the real world that he changes his tone, his accent and word choices when communicating with peers, professionals, teens and others who he is meeting with, to feel included. At times this behaviour is conscious and at others appears to be unconscious. This question was designed to show that human mimicry occurs in an online context as well.

Out of 46 responses received, 23 respondents (50\%) indicated that they changed their communication style, language and choice of words to fit in with the person or group they were communicating with. For example:

Question2 [0-270]

I tend to communicate in particular ways with particular groups of people in any situations, the language which I use with friends and family is more relaxed, however with colleagues I tend to be more formal, however this is not a Facebook specific communication change. Question2 [2480-2678]

Some people, especially old colleagues, I communicate with more formally than mates. I tend to only befriend people I actually know and then interact with them online the way I would in real life.

Question2 [3544-3837]

I'm 50 but I have some facebook friends who are in their late teens through to their thirties (online gaming friends) and my language certainly changes. I have succumbed to using 'online language' (LOL, ROFL etc etc). Why? Because it easy, its understood, and probably because its expected. 
Those who stated that they did not engage in mimicry or imitation numbered 18 or $40 \%$ of respondents, but given the nature of unconscious mimicry, it is possible that some of these respondents do engage in such behaviour without being consciously aware of it. Three of the respondents gave reasons for not adapting their language, grammar and word choices:

Question2 [271-317]

I am who I am, no changes in language or style

Question2 [3229-3326]

In a virtual world, behind the computer, I intended to be my ideal self rather than the real one.

Question2 [4524-4549]

I am always myself online

In most cases there was no indication on the part of the respondent as to whether this was an unconscious behaviour or whether the behaviour was conscious and deliberate. One or two respondents did give a clue about their behaviours being conscious or unconscious but most did not:

Question2 [1416-1546]

Always careful on what is placed as a comment, to try to avoid offending them. It is an open site and your comments may be seen by others. (Could be interpreted as being conscious imitation)

Question2 [1137-1230]

I believe that sometimes change our language and style as a subconscious empathetic response. (Could be interpreted as unconscious mimicry)

From these results it is unclear whether the majority of these reported behaviours are imitation or mimicry, or a combination of both. This is important to ascertain as the literature differentiates between mimicry which is unconscious in nature and imitation which is a conscious and deliberate behaviour (van Baaren, et al., 2009) and (Gabriel, et al., 2010). Unconscious mimicry is a mechanism for gaining acceptance by others in the real world (van Baaren, et al., 2009). What is also not clear from these results is the motivation for this mimicry or imitation. Are these behaviours designed to express one more clearly in the online world of text messaging to ensure that one is being understood? Or is it about being accepted and included by the person or the group being communicated with. Two respondents did give a clear picture of their motivations for this behaviour: 


\section{Question2 [1547-1652]}

To I guess be perceived by a certain group of people in a certain way. Which is in a way a bit superficial. (The motivation here appears to be acceptance and belonging)

Question2 [2255-2379]

The only time I have changed my language and style when communicating on Facebook is to ensure that I am clearly understood. (The motivation here is clearly about being understood)

While the focus of this question was on human mimicry, it became apparent from a number of respondents that while online communities do exist, an online community is not like a group in the real word. This is because communication in the real world is dependent on body language, facial expressions and tone of voice. On Facebook the mode of communication is text, and this removes the effect of body language from communication, making it difficult to interpret the mood and intent of the sender. Suler, (2004) states that communicating online does not involve the five senses that are engaged during face-to-face communications. This has resulted in the erosion of an individual's "self-boundary" online. This ability to distinguish between self and the outside word disappears online due to the absence of forms of non-verbal communication and there is a tendency to openly share information that one would normally keep secret.

These differences could result in the dehumanisation of online communities to the extent that online social affiliation needs are less powerful than they are in the real world. This might also offer some explanation as to why people do not mimic each other online. If social affiliation needs online are less powerful than in the real world, then there is little need to mimic others as a way of being accepted online.

These differences between online and offline communities were demonstrated by the following comments:

\section{Question2 [319-418]}

There is a difference between speech and text. When texting one chooses ones words more carefully.

\section{Question2 [1942-2197]}

I have had to resort to "smileys" or this sort of thing: :-), :-P etc in order to give some semblance of facial expression to show I'm joking etc. If I hadn't done this sort of thing, I would risk being misunderstood when communicating with someone else. 
Question2 [639-784]

Most messages between humans are communicated via body language. What you do or the expressions say far more than words. Text doesn't have that.

The Likert Scale data indicates strong resistance to the notion that online behaviours by the respondents of this survey are unconscious and automatic. This indicates that it is likely that the behaviours mentioned in the freeform section above (in the absence of more information) are a deliberate and conscious form of imitation rather than mimicry.

However, more information is required on the motivation for these behaviours and whether they are conscious or unconscious, before an informed conclusion can be reached.

In the next question attention is given to the question of personal safety and privacy online. 


\section{Likert Scale Question 4: I am unconcerned about my personal safety because I have found a strong sense of acceptance, belonging and friendship online.}

\begin{tabular}{|c|c|c|c|}
\hline$\#$ & Answer & Response & $\%$ \\
\hline 1 & $\begin{array}{l}\text { Strongly } \\
\text { Disagree }\end{array}$ & 10 & $16 \%$ \\
\hline 2 & Disagree & 24 & $39 \%$ \\
\hline 3 & $\begin{array}{l}\text { Neither } \\
\text { Agree nor } \\
\text { Disagree }\end{array}$ & 17 & $28 \%$ \\
\hline 4 & Agree & 9 & $15 \%$ \\
\hline 5 & $\begin{array}{l}\text { Strongly } \\
\text { Agree }\end{array}$ & 1 & $2 \%$ \\
\hline & Total & 61 & $100 \%$ \\
\hline
\end{tabular}

This question was designed to measure the perception of respondents towards online affiliation and personal safety (incorporating privacy) online. Does social affiliation offset the need for personal safety online?

The strong sense of online community and belonging online reported in Likert Question 1 above has not created a sense of security among Facebook users surveyed. Of the 61 responses received, 55\% of the participants either "disagreed" or "strongly disagreed" that they were unconcerned with personal safety online. For them personal safety online is a concern. This argument is strengthened by the responses in Likert Scale Question 3 which implied that $76 \%$ of respondents are concerned with personal safety online, since they consciously think about and decide who to admit as Facebook friends.

The qualitative analysis of the freeform question relating to the Likert Scale Questions 4 appears below: 


\section{Freeform Question 3: Personal Safety vs Social Affiliation online}

This question was designed to establish whether there is an awareness of personal safety issues online, and to ascertain how respondents protect themselves against these threats. The finding on the freeform question adds strength to the Likert scale Q3 and Q4 arguments that people are concerned with their privacy and personal safety online. Furthermore online social affiliation seems not to lessen the need for online protection. Responses were received from 52 people. Respondents used a range of techniques to protect themselves online. There are those who gain a sense of security by configuring their Facebook privacy settings (42\%): Question3 [3884-4049] I had multiple lists for what I will share. This is not related to safety, rather privacy. If I wouldn't share with someone in person, I don't share on FB with them.

Question3 [1227-1350]

Set the security to friends only for all items, and customised my contact information that only I can see the information.

Question3 [4874-5002]

Select all the secure options - block apps and do not follow links to weird stuff....this survey nearly ended up in that bucket!

Question3 [88-248]

I also have very private profile settings on Facebook and regularly check the privacy settings to make sure my personal content is not available to the public.

The literature has demonstrated that while Facebook members often do take steps to configure their privacy settings, there are those who really do not know how (Collins, 2010).

There are also those under the illusion of being secure after having attempted to configure their privacy settings (Barnes, 2006) and (Collins, 2010). The settings they use leave them exposed to the risks:

Question3 [3566-3699]

I have checked recently that the http has an "s" as well to protect my security and only have "friends of friends" who can look me up.

Others will limit the amount of information they publish online (38\%):

Question3 [950-1066] 
Very careful about what I write on line. I also believe that more personal matters should never be discussed online

Question3 [2299-2412]

I have asked others to take down photos with my children in them or removed tags so they cannot be linked to me.

Question3 [4523-4640]

I think about what I say before posting any comments as I do not want people to know the intimate details of my life.

Question3 [6503-6746]

I limit what I publish. I would never publish info or photos that I wasn't happy to have published worldwide. Occasionally some friends may publish photos of you that you're not happy with and you can ask them to 'untag' you or remove them

Question3 [3494-3566]

No sensitive details (addresses, phone no's etc) are posted online.

Controlling the content of what a person posts online is an effective way of protecting one's personal safety and privacy online. This is of extreme importance because many organisations have uses for information mined from Facebook or sold to them (Palvia \& Pancaro, 2010), (Preibusch, et al., 2007) and (Wills \& Reeves, 2009).

One of the most interesting outcomes of this research was the fact that $37 \%$ of people surveyed felt a sense of security by only inviting people they already know and trust, or have had an association with in the past, to become friends, and largely ignored requests from people they did not know. There were respondents who did not configure privacy settings at all, but took extra care to only admit people they knew as friends on Facebook. Of the 52 responses to this question, 17 respondents (32\%) indicated that they only admitted friends they already knew:

Question3 [1067-1163]

I only accept friend requests from people I know and won't randomly meet anyone who I don't know

Question3 [3174-3297]

I only befriend people who I am actually friends with or people who I have met and whose company I enjoyed when I met them.

Question3 [2176-2234] 
I only accept friend requests from people I actually know.

This ties in with the literature where the "Illusion of Privacy" on the internet is discussed (Barnes, 2006). People assume that their information is only visible by the friends they have admitted online. While Facebook users may think they are only communicating online with trusted friends, they are often not aware that a potentially infinite audience may be able to access their data and monitor their online conversations (Barnes, 2006), (Mital, et al., 2010) and (Gray \& Christiansen, 2009).

Both the Likert data and the freeform data concur that people are aware of the personal safety and privacy issues, and are taking steps with varying degrees of effectiveness to protect themselves online.

More information will need to be extracted from the interviews to determine whether by admitting only friends that one knows in real life, that privacy settings take on lesser importance.

Attention will now be turned to the question of trust and shared values as possible drivers of risky online behaviour. Likert Scale Question 5 investigates the likelihood that Facebook members will compromise their values to gain acceptance in online communities. Likert Scale Question 6 considers the possibility that the impact of shared values on social affiliation in the online context, are as powerful as they are in the real world. 


\section{Likert Scale Question 5: If there is an expectation among my online friends to behave in ways that contradict my personal beliefs and values, I conform in an attempt to feel accepted.}

\begin{tabular}{|c|c|c|c|}
\hline$\#$ & Answer & Response & $\%$ \\
\hline 1 & $\begin{array}{l}\text { Strongly } \\
\text { Disagree }\end{array}$ & 23 & $38 \%$ \\
\hline 2 & Disagree & 31 & $51 \%$ \\
\hline 3 & $\begin{array}{l}\text { Neither } \\
\text { Agree nor } \\
\text { Disagree }\end{array}$ & 6 & $10 \%$ \\
\hline 4 & Agree & 0 & $0 \%$ \\
\hline 5 & $\begin{array}{l}\text { Strongly } \\
\text { Agree }\end{array}$ & 1 & $2 \%$ \\
\hline & Total & 61 & $100 \%$ \\
\hline
\end{tabular}

This question is the first of three designed to measure the importance of values. It can be assumed that if there are online affiliation needs there may be pressure on a respondent to let go of certain values if the person is to be permitted to affiliate with that online community.

When one considers the result of this question it indicates that $89 \%$ of people will not compromise their values online in order to fulfill their need for affiliation. This indicates that online friendships are based on shared values or value congruence. (Cazier, et al., 2007).

A further possibility is that the need for affiliation in online communities is not as powerful as it is in real world groups. Likert Scale Question 1 demonstrated that the majority of respondents acknowledged the existence of online groups, but while there were similarities, they were different because of the lack of body language and other forms of non-verbal communication in the online context. It is possible in this context that respondents were motivated more to hold on to their values even if faced by the threat of rejection, because the need for affiliation online is less powerful than it is in the real world. 


\section{Likert Scale Question 6: If I am ostracized by my online friends, I will do whatever it takes for me to be accepted again.}

\begin{tabular}{|c|c|c|c|}
\hline$\#$ & Answer & Response & $\%$ \\
\hline 1 & $\begin{array}{l}\text { Strongly } \\
\text { Disagree }\end{array}$ & 29 & $48 \%$ \\
\hline 2 & Disagree & 21 & $34 \%$ \\
\hline 3 & $\begin{array}{l}\text { Neither } \\
\text { Agree nor } \\
\text { Disagree }\end{array}$ & 8 & $13 \%$ \\
\hline 4 & Agree & 3 & $5 \%$ \\
\hline 5 & $\begin{array}{l}\text { Strongly } \\
\text { Agree }\end{array}$ & 0 & $0 \%$ \\
\hline & Total & 61 & $100 \%$ \\
\hline
\end{tabular}

In examining online behaviours , $82 \%$ of respondents either "disagreed" or "strongly disagreed" that they would compromise their values to gain acceptance online after being ostracized. This confirms the findings in Likert Scale Question 5 above that $89 \%$ of people will not compromise their values online in order to fulfill their need for affiliation. This indicates once again that there is compelling evidence that online friendships are based on shared values or value congruence (Cazier, et al., 2007). In research carried out in ecommerce if was found that value congruence builds trust, resulting in consumers parting with more personal information online (Cazier, et al., 2007). From this result it appears that online friendship is strongly values driven and survey respondents choose their online friends with care. A further consideration, as was discussed in the previous question, is the possibility that the need for online affiliation is less powerful than in the real world and as a result people will not compromise their values to be re-accepted into online communities. 
Since value congruence leads to trust, the next question was designed to gain a perspective on whether trust plays a role in determining online behaviours.

\section{Likert Scale Question 7: I share controversial information with my online community because I trust them.}

\begin{tabular}{|c|c|c|c|}
\hline$\#$ & Answer & Response & $\%$ \\
\hline 1 & $\begin{array}{l}\text { Strongly } \\
\text { Disagree }\end{array}$ & 13 & $21 \%$ \\
\hline 2 & Disagree & 25 & $41 \%$ \\
\hline 3 & $\begin{array}{l}\text { Neither } \\
\text { Agree nor } \\
\text { Disagree }\end{array}$ & 14 & $23 \%$ \\
\hline 4 & Agree & 9 & $15 \%$ \\
\hline 5 & $\begin{array}{l}\text { Strongly } \\
\text { Agree }\end{array}$ & 0 & $0 \%$ \\
\hline & Total & 61 & $100 \%$ \\
\hline
\end{tabular}

At first glance, the responses to this question with $62 \%$ disagreeing that they share controversial information online with people they trust, seemed to pour cold water on the concept that it is trust that drives the behaviour of revealing too much personal information online, and yet in the next question there was agreement among $75 \%$ of the respondents that people do share personal information online with people they trust. The only difference between this question and Likert Question 8 was the word "controversial". This raises the possibility that survey respondents assessed the word "controversial" in terms of their own personal values in this question. Respondents have already indicated very clearly that they will not compromise their personal values online. If the idea of sharing controversial information online is in violation of those values it could be concluded that respondents would not share controversial information even with those who they trust. Of the responses received to this question, $62 \%$ "disagreed" or "strongly disagreed" that trusting the online 
community would result in them sharing of controversial information online. This indicates a violation of personal values by the word "controversial", making respondents reluctant to share such information online. This also indicates the importance of choosing online friends who reflect one's own values online.

The following question is about establishing whether the respondent will share personal information online with trusted friends on Facebook.

\section{Likert Scale Question 8: I only share personal information online with the Facebook friends I trust}

\begin{tabular}{|c|c|c|c|}
\hline \# & Answer & Response & $\%$ \\
\hline 1 & $\begin{array}{l}\text { Strongly } \\
\text { Disagree }\end{array}$ & 3 & $5 \%$ \\
\hline 2 & Disagree & 6 & $10 \%$ \\
\hline 3 & $\begin{array}{l}\text { Neither } \\
\text { Agree nor } \\
\text { Disagree }\end{array}$ & 6 & $10 \%$ \\
\hline 4 & Agree & 32 & $53 \%$ \\
\hline 5 & $\begin{array}{l}\text { Strongly } \\
\text { Agree }\end{array}$ & 13 & $22 \%$ \\
\hline & Total & 60 & $100 \%$ \\
\hline
\end{tabular}

This question was designed to measure whether personal information that is not in conflict with one's values is freely shared online with friends the respondent trusts.

The $75 \%$ response of those who "agree" or "strongly" agree with the statement feel secure sharing personal information with people they trust online. This agrees with what has been written in the literature about sharing information with trusted friends online (Barnes, 2006), (Xiang, et al., 2010) and (Mital, et al., 2010). This evidence considered together with the response to Likert Scale Question 7 indicates there is a case for value congruence and trust being factors that influence the sharing of personal information online (Cazier, et al., 2007). 


\section{Freeform Question 4: Impact of values and trust on willingness to share information online.}

This question was designed to determine in the event that somebody has divulged information of a very personal nature online, whether that behaviour was influenced by the fact that they trusted the receiver of the information or whether it had to do with the fact that the user perceived the receiver as reflecting their own personal values. The majority of the 47 respondents $(51 \%)$ indicated that they have not divulged information of a personal nature online. Some of their comments include:

Question4 [1227-1290]

I dont actually share significant personal information on line.

Question4 [2136-2381]

I don't share much personal information on FB because even if I trust my friends, they may not have as strict rules about accepting friends and privacy settings as I do. I assume that whatever I post could be seen by anyone and post accordingly.

Question4 [1479-1603]

I do not share personal information on line, if it to be shared, will be done via a phone call or face to face communication

This indicates that the majority of respondents who took this survey do not divulge information of a personal nature online. This is in contradiction with what has been reported in the literature (Nosko, et al., 2010), (Kornblum \& Marklein, 2006) and (Acquisti \& Gross, 2006). However it should be noted that "personal information" has different meanings for different people. For example consider the different meanings attributed to "personal information" by a few respondents:

Question4 [1765-2170]

I don't share significant personal info beyond the names, birthday, email and contact info and a bit of likes and dislikes stuff of a bland nature.

Question1 [1331-1374]

I share pics with the family and friends.

Question3 [281-376]

I don't think my safety is at risk. What are people going to do with that info? Nothing really. Question3 [4192-4265]

I don't put photos of myself on the web or too much personal information. 


\section{Question3 [2984-3069]}

I have made my profile private and do not share any highly private information online The varying interpretations of what constitutes" information of a personal nature", may result in a significant number of users taking risks online without realising what they have done.

This finding of this freeform question 4 that $51 \%$ of respondents choose not to reveal much personal information online, is confirmed by the result of freeform question 3 that $38 \%$ of the participants surveyed on personal safety online, referred to limiting personal content online as a safety mechanism. See also the discussion on differing perceptions of the meaning of "personal information" that follows. If a universal definition for "personal information" existed many more respondents might realise they are sharing too much personal information online.

Of the remaining 23 respondents who acknowledged publishing significant information of a personal nature online, 13 respondents $(56 \%)$ shared this information because they trusted the recipients of this information:

Question4 [444-608]

Trusting my friends and family (all of the friends I have on facebook are people I know in person as well, I never ever friend people that I have not actually met).

Question4 [2655-2775]

I do trust my friends and I share some significant information but I use skype for sharing of real personal information

Question4 [1979-2135]

Probably more because I trusted them. Nobody has exactly the same kind of personal values that I do (indeed, I would be somewhat concerned if somebody did).

Of the 23 respondents who acknowledged publishing significant information of a personal nature online, 6 respondents (26\%) shared this information because they perceived the recipients of this information to share the same values as them

Question4 [3109-3173]

It more to do with the fact that they share your personal values

Question4 [4357-4443]

I don't reveal a lot of personal info, but if i do, it's because they share my values. 
The results in this freeform question reveal that trust and personal values do impact upon the extent to which personal information is revealed online, and confirms the evidence found in the 4 Likert Scale questions above about the importance of shared values.

It is probably appropriate to briefly revisit the literature for guidance on what constitutes "personal information". This can include profile information such as name, photographs, age, birthdates, sexual preference, relationship status, location, contact details as well as details and photographs (intimate and controversial) of events (Acquisti \& Gross, 2006), (Nosko, et al., 2010) and (Williams \& Merten, 2008).

So in the context of Facebook, some respondents were guarded about sharing personal information online, but completely disinhibited when it came to sharing contact details. Others are guarded about sharing photos but disinhibited about sharing other information. The literature considers the disinhibition effect in online communities (Suler, 2004). At the completely disinhibited end of the spectrum one respondent said:

Question3 [281-376]

I don't think my safety is at risk. What are people going to do with that info? Nothing really. So while these behaviours are reported in the context of Facebook, there exists the possibility that these same respondents may become more or less disinhibited when they find themselves in another online situation such as Linkedin (Suler, 2004).

However in the context of behaviours within Facebook, the results in this freeform question that reveal that trust and personal values do have an impact upon the extent to which personal information is revealed online, and confirms the strong evidence found in the Likert Scale questions 5, $6.7 \& 8$ above.

\section{Freeform Question 5: Concluding remarks}

Apart from a few comments in the first freeform question about Facebook being a timewaster, the comments about Facebook in this survey were generally positive and people seemed to gain some utility through its use. Interestingly respondents to this survey did not indicate their awareness of the fact that Facebook and other outside companies and individuals can easily mine the personal data of individuals, for sale to companies and 
organisations for whom that information has great value (Palvia \& Pancaro, 2010), (Preibusch, et al., 2007) and (Wills \& Reeves, 2009). One respondent in this survey said: Question5 [3214-3503]

Facebook and other sites are obvously collecting data in so many forms I wonder where this will all end up. Legally they are BAD and deceptive companies to be treated with the utmost caution.....Use the latest Anti Virus etc protection available and think twice before submitting anything!

In other freeform questions respondents seemed to be ignorant of the value their personal information has to marketing firms and other potential buyers. For example:

Question3 [268-500]

None really. I don't think my safety is at risk. What are people going to do with that info? Nothing really. And if I experience abuse I either block the abuser or shutdown my account. I'd be quite happy to shut my account tomorrow.

Question4 [1765-2170]

I don't share significant personal info beyond the names, birthday, email and contact info and a bit of likes and dislikes stuff of a bland nature.

There were a number of complaints about Facebook in the concluding remarks section. For example:

\section{Question5 [678-858]}

Facebook is definitely a revolution but it is frustrating trying not to reveal certain information on there with having mixture of friends, family, and colleagues able to view this Question5 [918-1093]

One final observation: I don't care if one of my friends is heading off to the supermarket to buy a loaf of bread. I don't need to know these sorts of things about my friends.

Question5 [1372-1524]

Facebook was a great tool when I felt isolated from my friendship group after shifting cities. But when I'm busy socially I find it to be frustrating.

\section{Question5 [2278-2643]}

I hate facebook and avoid using it. I only have Facebook as my daughter who is overseas always puts her photos on her Facebook page so I have to have Facebook to view them. If friends ask me if I will add them to my Facebook I will do so, but only so I won't offend them. I actively avoid using Facebook I do not like the concept of people lives being so 'visible'. 
Question5 [2914-3087]

Just like to check out now and then what my friends have been up but not a huge Facebook fan as I feel there are more important priorities than being on Facebook regularly.

It is a potential concern that the majority of respondents, who took this survey, did not indicate any awareness or concern about the sale or mining of personal data from within Facebook. More information is needed on this topic to draw any opinions. This may be a possible opportunity for the face-to-face interviews to uncover additional information.

\subsection{Summary of survey data and gaps in knowledge}

1. The majority of respondents to this survey reported a sense of community and belonging online. Opinions diverge on the question of the comparison between real world groupings and online communities. Some state that they are very similar while the majority suggest that there is very little similarity. The results indicate that the main difference between real world groups and online communities is the way in which people communicate with each other within those groupings. In the online world, the five senses are not utilised in communication and the absence of body language, tone of voice and other non-verbal cues often lead to misunderstandings. By contrast in the real world people communicate face-to face and engage the five senses extensively in communication (Suler, 2004). There was evidence to suggest that people try to rebuild their real world communities online. Respondents reported to belonging to online family groups, school groups and sporting groups that reflect the real world. Many also indicated that they only friend people on Facebook who are already trusted friends in the real world. It is logical to reason then, that there are online communities, but that these communities differ from real world groupings in some important respects. The survey result indicates that affiliation needs online are of lesser importance than in real world groups, and this may indicate why little evidence of human mimicry online could be found. Survey data did not appear to support $\mathrm{H} 1$ : that humans mimic online behaviours including risky behaviours to gain acceptance in online communities.

2. The survey data also indicates that even though people find a sense of community online and that while most only befriend people they already know and trust in the real world, the majority of respondents are concerned with their personal safety and privacy online indicating that personal safety online is of greater importance than 
social affiliation online. The survey data does not support H2: The need for personal safety online is secondary to the need for social affiliation. In spite of the risks, there was an indication that the majority of respondents were comfortable sharing information online with people they trust. While respondents seemed to be aware that there are risks online, there appeared to be some ignorance as to what those risks actually were.

3. On the question of online mimicry, the majority of respondents did not believe that any of their actions online were unconscious or automatic. A lot of thought and consideration was given to whom to admit as Facebook friends. The majority of respondents reported changing their communication styles online depending on who they were communication with. What did not emerge was their motivation for that behaviour or whether it was a conscious or unconscious behaviour. One could argue that because of the unconscious nature of mimicry, respondents may not be aware that they are engaging in mimicry online. One could also argue that out of an infinite number of behaviours that constitute mimicry, only three were considered in this research. What is also not clear is whether, as happens in the real world, people tend to mimic each other more on Facebook than on Linkedin or any forum or blog. There is inadequate evidence here to support $\mathrm{H} 1$ : That people mimic each other online to gain acceptance in online communities.

4. While the survey data demonstrated that both values and trust are important factors in determining the amount of personal information shared online, there was very strong support that people are not prepared to compromise their values online. This was demonstrated by the fact that the majority of respondents indicated sharing personal information online with trusted friends, but in the event that that the information to be shared was controversial, the majority of respondents indicated that they would not. The data offers strong support for H3: Humans reflect the values of their friends on social networks to gain their approval.

In order to gain more insight into the above findings, it was decided to interview eight frequent Facebook users.

\subsection{Analysis of Interview Data}

While the sample size was too small to make any generalizations from, the following interesting themes emerged which reinforced the findings reported in the survey data. 
1. There are similarities between online and real world communities but they differ from each other in some important respects:

Interview3 [83-816]

No similarities. When you meet somebody face-to-face you can sum them up, but when you meet somebody online, you have no idea who is on the other end of your conversation.

Communication online is very difficult in the absence of body language of other non-verbal cues. With nothing to evaluate the communication against there is a tendency to trust online communication, and I am aware of people who have been seriously hurt financially because they trusted an online communication.

Interview5 [83-1090]

In the real world, groups are clearly defined and exclusive, but online there is a lot of crossover between different groups. For example I have professional work colleagues who don't engage with my social friends in real life, who might not engage with my close family in real life. Yet online they become exposed to each other and can see other aspects of my life that they may not have been aware of as members of exclusive real world groups. Interview6 [83-541]

There are many similarities online when compared to the real world - mainly the fact of being accepted or rejected in life. Acceptance on Facebook is very important in particular among the teenagers and younger people.

Interview8 [83-1303]

The human need to belong is about needing to know that other people value me. When communicating with others, you need immediate feedback or response to affirm that you are valued and appreciated. In the offline context this is easier due to communicating by words, tone and body language. Online this need is not always met because of the delay in receiving feedback and the absence of any body language.

As expected from the survey results, the differences between online and offline communities is around communicating using the five senses and receiving instantaneous feedback in faceto-face meetings, versus the absence of body language, the use of online text language and delayed if any feedback. These findings agree with the literature on Cyber Psychology (Suler, 2004). Also of interest was the comment about the spillover of friends online belonging to different real world groups. This leads to the logical conclusion that online friendships can lead to the erosion of real world group boundaries. One respondent dealt with 
this problem by creating multiple profiles with pseudonyms, but this detracts from real world friendships:

Interview7 [1714-2213]

I would personally set my privacy settings and different profiles to ensure that people I trust can only access certain levels of information. I have different profiles using pseudonyms for different categories of friends. These are not my personal real life friends and they don't know my identity or where I live.

2. Mimicry or imitation. People do adapt their message and communicate using words, language, slang and grammar different from their own, when communicating with different people and groups online. In most cases this appears to be a conscious and deliberate choice and in others is considered by the respondent as being unconscious. Some see it as a mixture of conscious and unconscious behaviour. The motivation for these behaviours is more likely to be about being understood than about fitting in or being accepted.

Interview1 [510-912]

When I communicate online with my friends I am more relaxed and casual. When I communicate with my manager on Facebook I speak real proper. I use all of the internet slang online, because everybody uses and understands it. My friends know what LMAO or LOL means, but my manager might not, so I change my language so that he can understand. It's more about being understood and simplifying to save time.

Interview5 [1165-1755]

There is an online language similar to text that allows you to communicate in a very concise way. Unlike face to face communication it is much shorter and to the point. It can often be misinterpreted in the absence of any body language or tone, so I take care that when I do communicate that I write clearly with the receiver in mind. I can consciously control how it is interpreted to an extent by carefully considering the person to whom I am sending it.

Generally speaking though, I don't change my style online to match my listeners, but I do abbreviate my communication style online.

Interview8 [1376-1681]

Have a collection of 100 s of friends who can potentially receive a message. Different groupings of friends may view the same communication differently. Some may find it funny others offensive. So I moderate everything I say online. 
Yes - I do change the way I communicate online with different types of friends. I make these changes to be seen in a certain light and not to be seen as being different. Use it to relate to people better. It's about being part of the group and being accepted. It's about gaining respect in the social situation you are in.

3. Trust and privacy online. All but two interviewees only invited people they know and trust from the real world to become their friends on Facebook. In spite of having a trusted community online, they still felt the need to configure privacy settings to keep themselves safe online. The survey data indicated that the majority of people are prepared to share information online with trusted friend, but there is still a tendency to configure privacy settings. The interview data here confirms this. This could lead to the logical conclusion that personal information is shared online because people are lured into a false sense of security, believing that their privacy settings will protect them and that the only recipients of that personal information will be their trusted friends:

Interview2 [1180-1642]

I only invite real world friends who I trust, and friends of friends that I have heard about by reputation. I still set privacy settings despite the trust I have, but it's more about only allowing certain friends access to certain information.

Interview5 [1806-2351]

I am quite conservative in my choice of online friends. They are normally people who I engage with socially in the real world, or friends of friends who I know about or work colleagues. Only engage with people I know and trust. I monitor my privacy settings and my search ability on Google.

Interview1 [964-1545]

My privacy settings are configured so that if anybody searches for me they will only see my name and profile photo. I only accept people as friends on Facebook that I already know. I don't accept friends of friends. If I know them but don't really talk to them, I won't become friends.

The one respondent who invited anybody to become friend said the following: Interview8 [1732-2086]

I used to be much more selective, but I have changed. I never reject friendship invitations from anybody nowadays. The reason is that I say less of anything that people will find 
offensive because these days I moderate everything I have to say. I am less concerned with my privacy settings now than when I was selective about choosing friends I trust.

4. In the surveys it was apparent that people were aware of the existence of online risks, but displayed some ignorance as to what the risks actually were. It was decided to investigate this further by asking interviewees how they thought that Facebook as a free service to members, generated revenues and profits. The idea of this question was to discover whether interviewees were aware that Facebook generates significant revenues through the sale of personal information to marketing and other interested companies and organisations. It was interesting that seven out if the eight respondents had no idea about the sale of personal information by Facebook to interested parties. Most of the interviewees stated or assumed that advertising accounted for a major portion of Facebook's revenues. At least four of the eight interviewees acknowledged using applications and playing online games, and saw them only as advertising tools: Interview1 [1589-1836]

I guess through advertising. I will play games online and advertisers offer discounts. There is lots of free stuff on FB, and lots of advertisements. It's just a guess, I really don't know. They offer options to buy Facebook credits to play games.

Interview3 [1731-1830]

Advertising on side of pages must huge. I don't know and have never really thought about it. Interview4 [1499-1660]

Advertising on side bars. On the games - Scrabble is a free game. Smallville may be paid for. The short answer is that I have no idea how they fund themselves.

\section{Interview6 [1513-1682]}

Facebook is a household name - I guess they get it from advertising. I would hate to think they were selling my photos or personal information - but I really don't know.

Interview8 [2129-2412]

Advertising - so effective 100s of millions of users. Advertisements down the side of the page. Advertising of games on Facebook. They view information on aggregate - not looking at it personally. Use it as advertising potentially, to refine Facebook service. 
5. A final question was asked to find out if interviewees perceived Facebook as being more or less risky than other social networking sites, and whether interviewees would divulge more or less information depending on the online forum or media being used. Apart from one respondent viewing them all as being equally risky and one claiming never to publish any personal information online, the other respondents all agreed that what and how much information they published online was dependent on the social networking site being used:

Interview3 [1955-2362]

Linkedin is a business site and I would be comfortable sharing career information on there. That because its purpose is different. On Facebook you can have photos and information on your social life, there are many more users and lots of teenagers. Because Linkedin has a career focus it is different to Facebook and it is more likely that people will share information on there.

Interview4 [1784-2062]

I share no personal information on Facebook but with Linkedin, it is a professional network that I like to use. I have never heard of anything going wrong on Linkedin. Use it extensively for work. It serves a different purpose for a different community, and I I trust it more. Interview5 [2726-3235]

I share different information on different networks. Facebook offers good protection for its users, but I wouldn't post career or CV information on there. Linkedin is a professional Network and I wouldn't share information there on social aspects of my life. What you share is dependent on the site. I would be more likely to share personal information on Linkedin from a professional point of view. A number of years ago I used Bebo, but spam increased, it wasn't user friendly and I felt insecure on there.

Interview7 [2457-2641]

I think Linkedin is less risky than Facebook. I am more likely to share more professional information on Linkedin than on Facebook and more social information on Facebook than on Linkedin.

Interview8 [2537-2747]

Each medium (social networking site) has slightly different expectations of behaviour. What we share online is different on Facebook, Myspace and Linkedin. So the way you share information is dependent on these expectations. 


\subsection{Summary of interview data}

1. The interview data pointed to the possibility that the differences between online and real world groups are such that the five senses required to communicate effectively in face-to face communication are eroded in an online context. The logical conclusion here is that the need to belong in real world groups is not as strong or is not replicated online, meaning that there is limited scope online for human mimicry. So, H1: that humans mimic online behaviours including risky behaviours to gain acceptance in online communities is clearly not supported in the interview data either. This is further confirmed by the fact that interviewees in the majority consciously imitated rather than mimicked the behaviour of others online as a way of being clearly understood as opposed to being accepted. This confirms the survey findings.

2. The interview data is consistent with the findings of the survey data in that the responses of the majority of interviewees carefully select their online friends from their real world groups, and configure their privacy settings. These behaviours do not support H2: The need for personal safety online is secondary to the need for social affiliation. In spite of the risks, there was an indication that the majority of respondents were comfortable sharing information online with people they trust. While there is an awareness of the risks of sharing too much personal information online, interviewees like their counterparts in the surveys, were unaware of the nature of one of these risks. Of eight interviewees, seven were not aware that Facebook sells their personal information to other businesses, marketing companies and other interested organisations.

3. Whereas it was demonstrated in the surveys that respondents share more personal information online with people and communities that they trust and perceive as sharing their values, was clear in the interviews that interviewees trusted different social networks more or less than others, and varied the type of personal information they were prepared to post on those sites. A logical explanation for those behaviours may be that Facebook espouses similar values to those of one user whereas Linkedin espouses similar values to those of another user. This lends credence to H3: Humans reflect the values of their friends on social networks to gain their approval. What is clear was that people are more or less inhibited online depending on which social networking site they are engaging on (Suler, 2004). 


\section{Discussion}

\section{Using the disinhibition effect to interpret the results}

This research was designed based on the assumption that either users engage in online risky behaviours, or they do not. This research did not provide for the possibility that users may behave in different ways when faced by different online situations as discussed in the Cyber Psychology literature (Suler, 2004). The focus of this research, however, was on the behaviours of Facebook users only and in a number of different online experiences within Facebook. The way users behave and their tendency to reveal large quantities of personal information while engaging with others on Facebook, may be different when those self-same users engage with others on other social networking sites, blogs or other online communities. A user involved in one online experience may be more disinhibited when communicating with friends than communicating online with a parent, for example. Suler's definition of disinhibited and inhibited online behaviours can explain to some extent, why some of the behaviours measured in this research were mixed (Suler, 2004). While being asked to friend somebody they do not know, a user's behaviour might be suspicious and guarded, but at the same time that same user may be posting inappropriate photos of themselves on their walls. In the one online context, the user is not engaging in risky online behaviour, but in another context, that same user is engaging in what might be considered to be risky online behaviour. This research indicates that risky online behaviour is not a tendency for a specific user, but is dependent on the online situation being faced by that user (Suler, 2004).

\section{Similarities and differences between online and real world communities}

Online communities exist and are similar to some extent with real world groups. However, these groupings are also very different, particularly in the way people communicate. In the real world people meet face-to- face and communicate using a rich tapestry of verbal and non-verbal cues. Body language, tone, facial expressions, enthusiasm and emotion all add to understanding of the message being received. However, online communication is an abbreviated online language with its roots in text. This leads to messages being misinterpreted as there is no guidance from the communicator's body language to help the receiver with interpretation. In other words, online the five senses do not come into play and this blurs the delineation of a person's personal boundary (Suler, 2004). While it was not the specific intent of this research to consider the impact of online communities on the blurring of the boundary between the self and the outside world, Suler argues that this may be the 
reason why people reveal information online that is normally kept secret in the real world (Suler, 2004). There is also evidence in the survey data that people divulge different information in different online contexts, like when using different media. Perhaps this is why there is not a universal behaviour that each person displays. What this means is that people behave differently depending on the type of online situation they find themselves in. So some people may be risky in one context and guarded in another. This theme on the differences between online and real world social groups and the absence of body language in online communication surfaced numerous times in both the interviews and surveys. The possible impact of the erosion of personal boundary on people divulging too much personal information online is an avenue for future research (Suler, 2004). This also raises the question that without the face-to-face interaction online, the need to affiliate with online social groups may not be as powerful as the need to affiliate with groups in the real world.

\section{Inadequate support for online mimicry}

Motivations for changing to online language when communicating with others were mixed with some respondents indicating that they made these adaptions in order to be understood, while others made these changes to be accepted. There were also mixed responses as to whether these adaptions and changes were consciously and deliberately thought out, or if they occurred without any conscious effort. The majority of interviewees acknowledged a process of self-moderation before sending out an online message indicating that the action was deliberate. It seems then that there is little evidence of mimicry online and very little demonstrating that in the case that people do mimic each other, acceptance rather than being understood, is the motivation for this behaviour. This does not entirely discount the possibility of human mimicry online, because due to its unconscious nature, people may not be aware of their behaviour and this makes it difficult to measure. The other interesting discovery in this research is that people often behave riskily on one situation but are very guarded or cautious in another. It seems that a person cannot be stereotyped as being either a risky or a cautious person online. A person on Linkedin may feel uninhibited for example, but that same person may be very inhibited on Facebook. So an individual will behave in different ways depending on the media used. This may account for the fact that no clear trends emerged in this research. It is possible that if the focus of the surveys and interviews shifted away from Facebook to some other forum, the same sample of respondents may have answered very differently. 


\section{Trust in online communities}

Most individuals interviewed or surveyed selected their online friends carefully, and these people were family and friends in the real world too. They were concerned with their privacy settings, but persisted in sharing information online with people they trusted. This indicates that if the circle of online friends is well known and trusted, and security settings are configured, people are lulled into a false sense of security online (Barnes, 2006). Interesting too is that all of the respondents either knew or assumed that Facebook generates revenues from advertising. Some had no idea at all and had never given that question any thought. All but one of the respondents was completely unaware that personal information could be sold to other companies by Facebook (Palvia \& Pancaro, 2010), (Preibusch, et al., 2007) and (Wills \& Reeves, 2009).

\section{Importance of Shared Values}

The basis of good friendship in the real world is that it is values driven. That, and the choice of friends from the real world, indicates that trust and shared values are brought online resulting in respondents sharing more personal information about them online. This has been demonstrated in the literature in both the real world and online context from an organisational perspective (Cazier, et al., 2007), (Verma, 2009), (Pirson \& Malhotra, 2008) and (Posner, 2010). The survey data demonstrated the importance of values to the respondents. No linkages could be found between shared - values and affiliation. In the surveys there was a strong assertion that values would not be compromised in any attempt to gain a sense of affiliation in online communities. The values were more important to respondents than the prospect of being accepted or rejected by an online group. The absence of any face-to-face interaction online makes online communities very different from their real world counterparts, and perhaps this lack of human contact decreases the power of the need to affiliate with online groups. The responses to the Likert questions demonstrated the lack of interest in online affiliation, but a keen interest in shared-values.

It is important to view the results of this research through the lens of the disinhibition effect (Suler, 2004). The results might be skewed since we have only looked at these behaviours in the context of a Facebook user in one or two situations. It is likely that in a slightly different online context or situation the behaviours of the self same respondents of the survey and the interviewees might well have been different. 


\section{Implications for business and future research}

The lessons learned from this research are important to businesses needing to understand their customers and in so doing providing better products and services to meet those needs. What clearly emerges from this research is that in certain circumstances people still do divulge personal information online. It is of importance to businesses to study the behaviours of people on social networking sites and other online forums to learn what it is that allows people to divulge personal information online.

In this research it was shown that people are more likely to share information online with people who share their values, or who they trust. These results are confirmed in the literature in studies carried out online and in the real world (Cazier, et al., 2007), (Caldwell, et al., 2009), (Pirson \& Malhotra, 2008) and (Posner, 2010). Businesses need to give more thought to transparency and to espouse their organisational values in their daily operations and on their websites. It is important that these values reflect the values of their customers.

More research is needed on online human mimicry as a way of gaining social affiliation online. This is such a powerful driver of human behaviour in the real world (Lakin, et al., 2008), (van Baaren, et al., 2009), (Kühn, et al., 2009), (Cialdini \& Goldstein, 2004) and (Kouzakova, Karremans, et al., 2010), that if a way could be found to lessen the differences between online communities and real world groups resulting in a more powerful need for online affiliation, companies could begin attracting more customers by mimicking their online behaviours.

Online New Zealand businesses and overseas companies with websites and forums accessible from within New Zealand could also build trust on their websites by upholding the principles of the New Zealand Privacy Act no 28 ("New Zealand Privacy Act," 1993). In particular if the companies intend building trust online they would do well to uphold Principle 3 of the Act which requires the company to seek the customer's consent to use that personal information, to explain what the information will be used for, as well as the identity of the intended recipient of that information ("New Zealand Privacy Act," 1993).

More research is needed on the disinhibition effect (Suler, 2004). From an organisational perspective businesses will need to build websites that provide a context or situation in which 
the majority of its customers feel safe and disinhibited. Perhaps that might be the design of online forums where people can maintain anonymity and / or invisibility as they engage with the business online.

\section{Conclusion}

The objective of this research was to gain some understanding of the reason why people indulge in the risky behaviour of sharing too much personal information online. Firstly there was the need to establish the existence of an online community. This was demonstrated to be true, but what emerged was the fact that while online and real world communities were similar to some extent, they were very different in a number of important respects. The major difference was in the way that members of these communities communicate with each other. In face-to-face communication, verbal communication is heavily reliant on body language, tone of voice and other non-verbal cues to ensure that the message is understood. Communication within online communities does not rely at all on body language and other non-verbal means to convey the message. In a sense, this dehumanizes the communication process and erodes the concept of "self-boundary" in humans which assists them in determining the boundary between the self and the rest of the world. Such boundaries in the real world are perceived using the five senses, but the five senses are no longer used in online communication resulting in the divulging online of information that would have been kept secret in the real world. The differences between real world groups and online communities have resulted in a decreased sense of social affiliation online. This means that people do not engage in human mimicry online as there is not as great a need to belong to online communities as there is in the real world. Online privacy is of great importance to people and most will configure their privacy setting even if their online friends are trusted and are also well known to tem in the real world. People are also very values driven and will not compromise their values to gain acceptance in online communities. This may also be the result of the decreased sense of social affiliation online. People are also more likely to share personal information online with friends they trust and this may be due in part to the illusion of being private while surrounded online by trusted friends. Each individual may display a range of online behaviours that range along a continuum of being risky to being ultracautious. How they behave is dependent on the online context in which they are engaging with others. As a result of this, it is possible that the results in this research might have been different if those behaviours had been considered in another context. 


\section{Bibliography}

Acquisti, A., \& Gross, R. (2006). Imagined communities: Awareness, information sharing, and privacy on the Facebook. Paper presented at the Proceedings of Privacy Enhancing Technology, Cambridge.

Barker, V. (2009). Older adolescents' motivations for social network site use: the influence of gender, group identity, and collective self-esteem. CyberPsychology \& Behavior, 12(2), 209-213.

Barnes, S. (2006). A privacy paradox: Social networking in the United States. . First Monday, 11 (9). Retrieved from http://www.uic.edu/htbin/cgiwrap/bin/ojs/index.php/fm/article/view/1394/1312

Baughman, L. L. (2010). Internet expression in the 21st Century: Friend request or foe? Confirming the misuse of internet and social networking sites by domestic violence perpetrators. Widener Law Journal, 19(3), 37. Retrieved from http://www.lexisnexis.com.helicon.vuw.ac.nz/hottopics/lnacademic/?verb=sr\&csi=15 $\underline{5885}$

Baumeister, R. F., \& Leary, M. R. (1995). The need to belong: Desire for interpersonal attachments as a fundamental human motivation. Psychological bulletin, 117, 497497.

Bergsieker, H. B., Shelton, J. N., \& Richeson, J. A. (2010). To be liked versus respected: Divergent goals in interracial interactions. Journal of Personality and Social Psychology, 99(2), 248-264.

Boyd, \& Ellison, N. B. (2007). Social network sites: Definition, history, and scholarship. . Journal of Computer-Mediated Communication, 13 (1). Retrieved from http://jcmc.indiana.edu/vol13/issue1/boyd.ellison.html

Boyd, \& Hargittai, E. (2010). Facebook privacy settings: Who cares? . First Monday, 15 (8). Retrieved from http://www.uic.edu/htbin/cgiwrap/bin/ojs/index.php/fm/article/view/3086/2589

Butler, T. (1998). Towards a hermeneutic method for interpretive research in information systems. Journal of Information Technology, 13(4), 285.

Caelli, K., Ray, L., \& Mill, J. (2008). 'Clear as Mud': Toward Greater Clarity in Generic Qualitative Research. International Journal of Qualitative Methods, 2(2), 1-13.

Cain, J., Scott, D., \& Akers, P. (2009). Pharmacy Students' Facebook Activity and Opinions Regarding Accountability and E-Professionalism. American Journal of Pharmaceutical Education, 73(6), 1.

Caldwell, C., Davids, B., \& Devine, J. A. (2009). Trust, faith and betrayal: Insights from management for the wise believer. Journal of Business Ethics, 84, 103-114.

Cazier, J. A., Shao, B. B. M., \& Louis, R. D. S. (2007). Sharing information and building trust through value congruence. Information Systems Frontiers, 9(5), 515-529.

Chai, S., Bagchi-Sen, S., Morrell, C., Rao, H., \& Upadhyaya, S. J. (2009). Internet and Online Information Privacy: An Exploratory Study of Preteens and Early Teens. Professional Communication, IEEE Transactions on, 52(2), 167-182.

Cialdini, R. B., \& Goldstein, N. J. (2004). SOCIAL INFLUENCE: Compliance and Conformity. Annual Review of Psychology, 55, 591.

Collins, J. C. (2010). Fortify Your Facebook Privacy Settings. Journal of Accountancy, 209(6), 42.

Dwyer, C., Hiltz, S. R., \& Passerini, K. (2007). Trust and privacy concern within social networking sites: A comparison of Facebook and MySpace. . Proceedings of AMCIS 
2007, Keystone, CO. Retrieved from

http://csis.pace.edu/ dwyer/research/DwyerAMCIS2007.pdf

Ellison, N. B., Steinfield, C., \& Lampe, C. (2007). The benefits of Facebook "friends:" Social capital and college students' use of online social network sites. Journal of Computer Mediated Communication, 12(4), 1143-1168.

Elzweig, B., \& Peeples, D. (2009). Using Social Networking Web Sites in Hiring and Retention Decisions. S.A.M. Advanced Management Journal, 74(4), 27.

Gabriel, S., Kawakami, K., Bartak, C., Kang, S. J., \& Mann, N. (2010). Negative SelfSynchronization: Will I Change to Be Like You When It Is Bad for Me? Journal of Personality and Social Psychology, 98(6), 857-871.

Gailliot, M. T., \& Baumeister, R. F. (2007). Self-esteem, belongingness, and worldview validation: Does belongingness exert a unique influence upon self-esteem? Journal of Research in Personality, 41(2), 327-345.

Gray, D., \& Christiansen, L. (2009). Protecting Adolescents' Personal Information Online: Constraints and Parameters. Journal of Information Privacy \& Security, 5(4), 31.

Gross, R., \& Acquisti, A. (2005). Information revelation and privacy in online social networks. Paper presented at the Proceedings of the ACM workshop on privacy in the electronic society, Virginia.

Hjorth, L. (2009). Web U2: Emerging Online Communities and Gendered Intimacy in the Asia-Pacific region. Knowledge, Technology \& Policy, 22(2), 117.

Hooper, A. S. C., \& Evans, T. B. (2009). The Value Congruence of Social Networking Services - a New Zealand Assessment of Ethical Information Handling. Paper presented at the Proceedings of the International Conference on Information Management and Evaluation, Cape Town.

Hovorka, D. S., \& Lee, A. S. (2010). Reframing interpretivism and positivism as understanding and explaining: Consequences for information systems research. Paper presented at the International Conference on Information Systems. from http://aisel.aisnet.org/icis2010_submissions/188

Kornblum, J., \& Marklein, M. B. (2006). What you say online could haunt you. . USA Today. Retrieved from http://www.usatoday.com/tech/news/internetprivacy/2006-03-08facebook-myspace X.htm

Kouzakova, M., Karremans, J. C., van Baaren, R. B., \& Knippenberg, A. (2010). A Stranger's Cold Shoulder Makes the Heart Grow Fonder: Why Not Being Mimicked by a Stranger Enhances Longstanding Relationship Evaluations. Social Psychological and Personality Science, 1(1), 87.

Kouzakova, M., van Baaren, R., \& van Knippenberg, A. (2010). Lack of behavioral imitation in human interactions enhances salivary cortisol levels. Hormones and behavior, 57(4-5), 421-426.

Kühn, S., Müller, B. C. N., van Baaren, R. B., Wietzker, A., Dijksterhuis, A., \& Brass, M. (2009). Why do I like you when you behave like me? Neural mechanisms mediating positive consequences of observing someone being imitated. Social neuroscience, 12, $1-9$.

Lakin, J. L., Chartrand, T. L., \& Arkin, R. M. (2008). I Am Too Just Like You. Psychological Science, 19(8), 816.

Leitch, C. (2003). Fighting a rearguard action? Reflections on the philosophy and practice of qualitative research in entrepreneurship. Organizational research Methods, 13(1), 6784.

Luo, L. (2010). Social Networking Websites: An Exploratory Study of Student Peer Socializing in an Online LIS Program. Journal of Education for Library and Information Science, 51(2), 86. 
Mital, M., Israel, D., \& Agarwal, S. (2010). Information exchange and information disclosure in social networking web sites: Mediating role of trust. Learning Organization, The, 17(6), 479-490.

New Zealand Privacy Act (1993). Retrieved 18 June, 2011, from http://www.legislation.govt.nz/act/public/1993/0028/latest/DLM296639.html

Nosko, A., Wood, E., \& Molema, S. (2010). All about me: Disclosure in online social networking profiles: The case of FACEBOOK. Computers in Human Behavior, 26(3), 406-418.

Onwuegbuzie, A., Johnson, R., \& Collins, K. (2009). Call for mixed analysis: A philosophical framework for combining qualitative and quantitative approaches. International Journal of Multiple Research Approaches, 3(2), 114.

Over, H., \& Carpenter, M. (2009). Priming third party ostracism increases affiliative imitation in children. Developmental Science, 12(3), F1-F8.

Palvia, S., \& Pancaro, R. (2010). Promises and Perils of Internet based Networking. Journal of Global Information Technology Management, 13(3), 1.

Park, J. H., Konana, P., Gu, B., \& Man Leung, A. C. (2010). An investigation of information sharing and seeking behaviors in virtual communities. Paper presented at the ICIS 2010 Proceedings. from http://aisel.aisnet.org/icis2010_submissions/242

Pirson, M., \& Malhotra, D. (2008). Unconventional Insights for Managing Stakeholder Trust. MIT Sloan Management Review, 49(4), 43.

Posner, B. (2010). Another Look at the Impact of Personal and Organizational Values Congruency. Journal of Business Ethics, 97, 535.

Preibusch, S., Hoser, B., Gürses, S., \& Berendt, B. (2007). Ubiquitous social networksopportunities and challenges for privacy-aware user modelling. Proceedings of Workshop on Data Mining for User Modeling., Corfu, Greece. Retrieved from http://vasarely.wiwi.hu-berlin.de/DM.UM07/Proceedings/05-Preibusch.pdf

Ridley, M. (1997). The origins of virtue: Human instincts and the evolution of cooperation. London: Penguin Books.

Stutzman, F. (2006). An evaluation of identity-sharing behavior in social network communities. Journal of the International Digital Media and Arts Association, 3 (1), 10-18. Retrieved from http://74.125.155.132/scholar?q=cache:D4ein5FwEAwJ:scholar.google.com/+stutzma $\underline{n} \& \mathrm{hl}=\mathrm{en} \& \mathrm{as} \_\mathrm{sdt}=2000$

Suar, D., \& Khuntia, R. (2010). Influence of Personal Values and Value Congruence on Unethical Practices and Work Behavior. Journal of Business Ethics, 97, 443-460.

Suler, J. (2004). The online disinhibition effect. CyberPsychology \& Behavior, 7(3), 321-326.

Toral, S. L., Martínez-Torres, M. R., Barrero, F., \& Cortés, F. (2009). An empirical study of the driving forces behind online communities. Internet Research, 19(4), 378-392.

van Baaren, R., Janssen, L., Chartrand, T. L., \& Dijksterhuis, A. (2009). Where is the love? The social aspects of mimicry. Philosophical Transactions of the Royal Society B: Biological Sciences, 364(1528), 2381.

Verma, H. (2009). Mission statements - a study of intent and influence. Journal of Services Research, 9(2), 153.

Wade, J. (2009). The New WILD WEST. Risk Management, 56(8), 26.

Weber, R. (2004). The Rhetoric of Positivism Versus Interpretivism: A Personal View. MIS Quarterly, 28(1), III.

Williams, A., \& Merten, M. (2008). A review of online social networking profiles by adolescents: Implications for future research and intervention. Adolescence, 43(170), 253. 
Wills, D., \& Reeves, S. (2009). Facebook as a political weapon: Information in social networks. British Politics, 4(2), 265.

Wortham, J. (2010). Facebook membership surpasses half a billion. International Herald Tribune, p. 17, from http://proquest.umi.com/pqdweb?did=2088387991\&Fmt=7\&clientId=7511\&RQT $=30$ 9\&VName=PQD

Xiang, R., Neville, J., \& Rogati, M. (2010). Modeling relationship strength in online social networks. Paper presented at the International World Wide Web Conference, Raleigh, North Carolina.

Zhang, Z. (2010). Feeling the sense of community in social networking usage. Engineering Management, IEEE Transactions on, 57(2), 225-239.

Zhou, T. (2011). Understanding online community user participation: a social influence perspective. Internet Research, 21(1), 67-81.

\section{Appendices - HEC forms}

Please proceed to page 70 for the:

- HEC Information Sheet for Interviewees

- HEC Information Sheet and Consent form for Survey participants

- HEC Consent form for Interviewees 


\section{MMIM 592 - Research Project in Information Management}

\section{Information Sheet for Interviewees}

As a friend on Facebook I would like to invite you to participate in the research project I am completing for my Master's degree in Information Management. The project investigates whether group behaviours online reflect group dynamics in the real world, and whether the need for social affiliation can explain the behaviour of people online. The research methodology involves the administration of a confidential semi-structured interview to a selection of my friends on Facebook. I really would appreciate it if you decide to participate in this interview.

\section{Please note the following points:}

1. In the reporting no individuals or organizations will be identifiable. Only the researcher, his supervisor and a third party transcriber will have access to the raw data. All data relating to this research will be stored securely and destroyed after two years.

2. Participants can receive a summary of the researcher's final report on request by providing their email address on the consent form below.

3. Prior to being interviewed each participant will be required to read this information sheet and provide the researcher with a signed consent form.

4. All data will be aggregated so that no individual or organisation can be identified.

5. The combined data may be presented at a conference or used in a journal article.

6. Interview participants have the right to withdraw their data from the project at any time before 22 May 2011

7. This research has been approved by the Ethics Committee of the School of Information Management.

Any questions about this project can be directed to the researcher's supervisor, Mr. Tony Hooper on 463- 5015 or email: tony.hooper@vuw.ac.nz, or to the researcher, Mr. Antony Zogg on 021425926 or email: zogganto@myvuw.ac.nz

\section{SCHOOL OF INFORMATION MANAGEMENT}


MMIM 592 - Research Project in Information Management

\section{Information Sheet for Online Survey participants}

As a friend on Facebook I would like to invite you to participate in the research project I am completing for my Master's degree in Information Management. The project investigates whether group behaviours online reflect group dynamics in the real world, and whether the need for social affiliation can explain the behaviour of people online. The research methodology involves the administration of a confidential online survey sent to all of my friends on Facebook. I really would appreciate it if you decide to participate in this online survey.

\section{Please note the following points:}

1. In the reporting no individuals or organizations will be identifiable. Only the researcher, his supervisor and a third party transcriber will have access to the raw data. All data relating to this research will be stored securely and destroyed after two years.

2. Participants can receive a summary of the researcher's final report on request by supplying their email address on the last page of the online survey.

3. Consent for participation in the online survey will be assumed when the survey questionnaire is completed.

4. All data will be aggregated so that no individual or organisation can be identified.

5. The combined data may be presented at a conference or used in a journal article.

6. Online survey participants have the right to withdraw their data from the project at any time prior to their completion of the survey

7. This research has been approved by the Ethics Committee of the School of Information Management.

Any questions about this project can be directed to the researcher's supervisor, Mr. Tony Hooper on 463- 5015 or email: tony.hooper@vuw.ac.nz, or to the researcher, Mr. Antony Zogg on 021425926 or email: zogganto@myvuw.ac.nz

\section{SCHOOL OF INFORMATION MANAGEMENT}


MMIM 592 - Research Project in Information Management

\section{Consent Form for Interview Participants}

I have read the attached Information Sheet and understand the nature of this research. I have had any questions about this research answered to my satisfaction. I understand that no personal identifying information will be recorded about me or my employer. I further understand that I can withdraw my consent from this research before 21 May 2011, and any data I have provided will be deleted.

I understand that the data I provide will be seen by the student's supervisor, Mr Tony Hooper. I further understand that the data I provide will be seen by a $3^{\text {rd }}$ party whose role it will be to transcribe this data. This person will be required to sign a non-disclosure agreement with the student.

If you wish to see a summarised report of the outcome of this investigation, please provide your email address here:

By signing this form I hereby give my consent to being interviewed by Antony Zogg (student's name) and to having the data I provide used confidentially in this research project.

\section{SCHOOL OF INFORMATION MANAGEMENT}

